\title{
Epigenetic regulation of the kappa opioid receptor by child abuse
}

Pierre-Eric Lutz ${ }^{1}$, Jeffrey A. Gross ${ }^{1}$, Sabine K. Dhir ${ }^{2}$, Gilles Maussion", Jennie Yang ${ }^{1}$,

Alexandre Bramoulle ${ }^{1}$, Gary G. Chen ${ }^{1}$, Michael J. Meaney ${ }^{2}$, and Gustavo Turecki ${ }^{1}$

${ }^{1}$ McGill Group for Suicide Studies, Douglas Mental Health University Institute, McGill University, 6875 LaSalle Boulevard, Verdun, Quebec, Canada, H4H 1R3

${ }^{2}$ Douglas Mental Health University Institute, McGill University, 6875 LaSalle Boulevard, Verdun, Quebec, Canada, H4H 1R3

Corresponding author: Gustavo Turecki

Email address: gustavo.turecki@mcgill.ca

Tel.: +1 5147616131 (ext.3311), Fax: +1 5147623023

Short title: The kappa opioid receptor and child abuse

Main text: 3664 words

Abstract: 250 words

5 Figures

0 Table

12 Supplementary Figures

8 Supplementary Tables

1 Supplementary material

72 References

Keywords: kappa opioid receptor, child abuse, DNA methylation, DNA hydroxymethylation, reporter assay, post-mortem 


\section{Abstract}

Background. Experiences of abuse and neglect during childhood are major predictors of the emergence of depressive and suicidal behaviors throughout life. The underlying biological mechanisms, however, remain poorly understood. Here, we focused on the opioid system as a potential brain substrate mediating these effects.

Methods. Post-mortem samples from three brain structures regulating social bonds and emotions were analysed. Groups were constituted of depressed individuals who died by suicide, with or without a history of severe child abuse, and of psychiatrically healthy controls. Expression of opioid peptides and receptors was measured using qPCR. DNA methylation, a major epigenetic mark, was investigated using targeted bisulfitesequencing, and characterized at functional level using in vitro reporter assays. Finally, oxidative bisulfite-sequencing was used to differentiate methylation and hydroxymethylation of DNA.

Results. A history of child abuse specifically associated in the anterior insula with a downregulation of the kappa opioid receptor (Kappa), as well as decreased DNA methylation in the second intron of the Kappa gene. In vitro assays further showed that this intron functions as a genomic enhancer where glucocorticoid receptor binding regulates Kappa expression, unravelling a new mechanism mediating the wellestablished interactions between endogenous opioids and stress. Finally, results showed that child abuse associated in the Kappa intron with a selective reduction in levels of DNA hydroxymethylation, likely mediating the observed downregulation of the receptor.

Conclusions. Altogether, our findings uncover new facets of Kappa physiology, whereby this receptor may be epigenetically regulated by stressful experiences, in particular as a function of early social life. 


\section{Introduction}

Social bonds are essential determinants of emotional well-being in humans (1-3). Accordingly, social exclusion or detrimental interpersonal relationships are major contributors to the risk of psychopathology. Recent evidence indicates that the peptidergic opioid system is a critical substrate encoding social experiences in the mammalian brain (4-6). In rodents, studies have shown that maternal attachment, interactions with congeners, social play, hierarchy and dominance, and pair bond maintenance in monogamous species are controlled by the mu (7-11) and, to a lesser extent, kappa $(12,13)$ opioid receptors. In primates, genetic variation in the mu opioid receptor $(\mathrm{Mu})$ modulates the expression of attachment behaviors, and the sensitivity to maternal separation $(6,14)$. Finally, in humans, imaging $(15,16)$ and clinical $(17)$ studies indicate that social rejection potentiates endogenous $\mathrm{Mu}$ signalling and is regulated by genetic polymorphisms in the corresponding gene (18). Beyond Mu, surprisingly, the potential role of other opioid receptors and peptides in relation to social experiences remains unexplored in humans.

Relationships with caretakers and parental figures represent prominent social bonds that determine the development of emotional regulation and sociability during early life $(19,20)$. Accordingly, experiences of abuse and neglect during childhood severely disrupt these processes and significantly increase the lifetime risk for numerous psychiatric disorders, including depression and suicide (21-24). The present study was designed to investigate the hypothesis that child abuse (CA) may trigger neuroadaptations in the opioid system. We systematically explored the expression and functional regulation of opioid receptor and peptide genes in brain regions that are activated during tasks involving social stimuli and are regulated by opioid signalling (2, 15, 16): the anterior insula (AI), the anterior cingulate cortex (ACC), and the mediodorsal thalamus (MDT). 
From a pathophysiological perspective, it remains a major challenge to understand how events that occur during childhood may contribute to behavioral dysregulation and psychopathology throughout life. Epigenetic regulation, such as DNA methylation, has recently emerged as a form of genomic memory that has the potential to mediate these long-term effects (25-27). Here, we demonstrate that severe experiences of $\mathrm{CA}$ associate with potent and specific transcriptional and epigenetic adaptations affecting the kappa opioid receptor (Kappa) gene. Specifically, we found that expression of Kappa is decreased in the Al of abused subjects, an effect that associated with decreased DNA methylation in an intron of the Kappa gene. Using in vitro reporter assays, we then demonstrate that this intronic locus is a potent enhancer site where Kappa expression is modulated by the glucocorticoid receptor (GR), a critical component of the hypothalamo-pituitary-adrenal (HPA) stress axis. Finally, we used oxidative bisulfite methodology (oxBS (28)) to differentiate two forms of DNA methylation, methylcytosine $(5 \mathrm{mC})$ and hydroxymethylcytosine $(5 \mathrm{hmC})$. Our results provide evidence that CA specifically affects levels of 5hmC in Kappa intron 2, likely accounting for the observed changes in receptor expression.

\section{Methods and Material}

\section{Study design}

Brain tissue was obtained from the Douglas-Bell Canada Brain Bank (http://douglasbrainbank.ca/). Transcriptional screening of the opioid system was performed in two steps. First, we compared two groups of subjects that were matched (Supplementary Table 1) for age, gender, $\mathrm{pH}$, post-mortem interval (PMI) and RNA integrity number (RIN): (i) individuals with a history of severe CA who died by suicide (CA) and (ii) psychiatrically healthy individuals who died suddenly from accidental causes and who constituted our control group (C). In a second step, to differentiate the 
effects of CA from those of suicide and associated psychopathology, we included a third group of individuals with no history of CA who died by suicide (SNA). Psychological autopsies were performed as described previously (29-35). Characterization of early-life histories was based on an adapted version of the Childhood Experience of Care and Abuse (CECA) interview that assesses various dimensions of childhood experience, including sexual and physical abuse, as well as neglect $(36,37)$. We considered as severe adversity reports of non-random major physical and/or sexual abuse during childhood (up to 15 years). Only cases with the maximum severity ratings of 1 and 2 (out of 6 , with 6 being absence) were included. Histories of abuse were validated with reports from medical charts, coroner files or reports from youth protection services when available. Dissections of brain tissue were performed as described in supplementary material.

\section{Quantification of Gene Expression Using Real-Time Polymerase Chain Reaction (RT-PCR)}

RT-PCR was performed as previously described (38). Briefly, RNA was extracted from homogenized brain tissue samples using the RNeasy Lipid Tissue Mini Kit (Qiagen). Extracted RNA was reverse-transcribed using M-MLV reverse transcriptase (Invitrogen ${ }^{\mathrm{TM}}$ ), and $\mathrm{CDNA}$ quantities were measured by RT-PCR using SYBR® Green DNA intercalating dye and master mix (Bio-Rad) and the $A B I 7900 H T$ machine (see Supplementary Table 2 for primers sequences, and Fig.S1 for calibration curves and PCR efficiencies).

\section{DNA Methylation Analysis}


DNA methylation was measured as described by Masser et al (39) (see Supplementary Material). Briefly, genomic DNA from each subject was extracted from the Al, bisulfite converted, and amplified by PCR (Supplementary Table 5). Next, PCR amplicons were purified by AMPure Beads, pooled and used for library preparations using NEXTERA XT (Illumina). Finally, libraries were indexed by PCR, purified and quantified using a BioAnalyser (Agilent). All libraries were pooled based on their molarity and sequenced on an Illumina MiSeq sequencer using the v3 kit (300bp paired-end).

\section{Hydroxymethylcytosine Analysis (oxBS)}

We performed an analysis of $5 \mathrm{mC}$ and $5 \mathrm{hmC}$ using the True Methyl kit (Cambridge Epigenetix), as recently described (40). Samples were prepared by pooling DNA from 2 subjects belonging to the same C, CA or SNA group. DNA from each pool was then split in 2 equal reactions, one of which underwent chemical oxidation followed by bisulfite conversion (oxBS-DNA), while the other underwent mock oxidation followed by bisulfite conversion (BS-DNA). Digestion controls and sequencing controls were processed as per the manufacturer's recommendations (Fig.S12). For library preparation, we used a PCR-based approach recently implemented by our group (41) (see Supplementary Material and Supplementary Table 6). Customized sequencing primers (Supplementary Table 7) were used in combination with a MiSeq v3 kit (300bp paired-end).

\section{Bioinformatic analysis}

Adaptors and primers were trimmed from the reads using Trimmomatic 0.35. Reads were also trimmed when Phred quality scores dropped below 20. Bismark v0.14.4 was used to align reads to the $\mathrm{hg} 19$ reference genome and to extract the number

of unconverted and converted cytosine for each CG. In NEXTERA experiments, the DNA methylation percentage was calculated for each cytosine as the unconverted 
cytosine read counts divided by total read counts (cytosines + thymines). In oxBS experiments, the $5 \mathrm{mC}$ percentage of each cytosine was calculated from the oxBS reaction as the unconverted read counts divided by total read counts. The $5 \mathrm{hmC}$ percentage was derived by subtracting the unconverted read counts in oxBS reaction to the unconverted read counts in BS reaction.

\section{Luciferase Assays}

A 850-bp sequence from Kappa intron2 was amplified from genomic DNA by PCR, digested and ligated into luciferase reporter vectors. In vitro DNA methylation of the constructs was carried out using the M.SssI CG Methyltransferase (NEB), and confirmed by restriction digestion (Hpall, NEB). The constructs were then transfected in SK-N-AS or in HeLa cells, and luciferase activity was measured $24 \mathrm{~h}$ later. The relative luciferase activity was calculated as the ratio Lucia-luciferase/Firefly-luciferase activity, for normalization by transfection efficacy.

\section{Statistical Analyses}

Statistical analyses were carried out with the IBM Statistical Package for the Social Sciences package and GraphPad Prism. For RT-PCR, a general linear model was used to analyse gene expression differences as a function of histories of suicide and CA. Pearson correlations between clinical confounders (age, gender, RIN, PMI, and pH) and gene expression levels were assessed for each gene, and only those variables showing a significant correlation were included in each final model (Supplementary Tables 3-4 and Fig.S3). For in vitro assays, one- and two-way ANOVAs were used to analyse the effects of vectors, patch-methylation, and dexamethasone (DXM), according to the experimental design. For DNA methylation studies, two-way ANOVAs with repeated measures were used to analyse differences among groups (between-subject factor) and 
among successive CG methylation sites (within-subject factor). Statistical significance was set at $p<0.05$.

\section{Results}

Decreased expression of Kappa specifically associates with a history of child abuse

Using RT-PCR, we first compared among $\mathrm{C}$ and CA groups the expression of 6 opioid genes (proopiomelanocortin, POMC; proenkephalin, Enk; prodynorphin, Dyn; delta opioid receptor, Delta; Mu; and Kappa) in 3 brain regions: ACC, AI, and DMT. Dyn expression in the MDT was very low (Ct values $>>30$ ), and was excluded from this initial screening. A Bonferroni correction for multiple testing was applied to the 17 remaining comparisons.

In the ACC, we did not find any difference in gene expression between $C(N=26)$ and $\mathrm{CA}(\mathrm{N}=26)$ groups (Fig.1A). In the MDT, there was an increase in the expression of the delta opioid receptor in $\mathrm{CA}(\mathrm{N}=26)$ subjects compared to $\mathrm{C}(\mathrm{N}=27)[\mathrm{F}(1,52)=6.84$; $p=0.012]$, an effect that did not pass Bonferroni correction (padj=0.20) and was not investigated further. In the Al we found that expression of Kappa was decreased in the CA $(N=30)$ group compared to $C(N=34) \quad[F(1,62)=9.73 ; p=0.00276 ; p a d j=0.0470]$ (Fig.1C).

To determine whether the latter Kappa adaptation specifically associated with CA or more generally with suicide and associated psychopathology, we conducted further analyses while incorporating a third group composed of individuals who died by suicide without histories of early-life adversity (SNA, N=32, Fig.2). To gain deeper insight into the transcriptional regulation of this gene, we quantified both the Kappa variant1 (NM_000912.4) and variant2 (NM_001282904.1), as well as the combined expression of both variants (see Fig.S4). Results indicated that the combined expression of 
variants1\&2 (Fig.2B, left panel) was significantly decreased as a function of $C A[F(1$, $92)=6.58 ; p=0.012]$, but not of suicide $[F(1,92)=0.032 ; p=0.86]$. Similarly, expression of Kappa variant 1 (Fig.2B, middle panel) was significantly predicted by $C A[F(1,92)=9.64$; $\mathrm{p}=0.003)]$, but not suicide $[\mathrm{F}(1,92)=0.21 ; \mathrm{p}=0.65]$. In contrast, we found that neither $\mathrm{CA}$ $[F(1,92)=2.86 ; \quad p=0.094]$ nor suicide $[F(1,92)=0.22 ; \quad p=0.88]$ showed significant associations with the expression of Kappa variant 2 (Fig.2B, right panel).

\section{Decreased DNA methylation in Kappa Intron2 specifically associates with a history of child abuse}

To investigate epigenetic mechanisms underlying decreased Kappa expression following $\mathrm{CA}$, we measured DNA methylation across 7 regions of the Kappa gene using a targeted bisulfite-sequencing approach. We achieved single-base resolution and high coverage (Fig.S5) at 169 CG dinucleotides located in: every exon, the promoter region upstream the TSS, and an additional cluster of CGs in intron2 of variant1 (Fig.2A).

We first investigated correlations between average DNA methylation in each region and Kappa expression (Fig.2C). The combined variants1\&2 expression showed moderately significant linear correlations with DNA methylation in intron2 of Kappa variant1 (Kappa-i2, $r^{2}=0.043, p=0.0468$ ) and in the additional exon that is specifically incorporated in Kappa variant2 (Kappa-ev2, $r^{2}=0.043, p=0.0469$ ). Importantly, these correlations appeared stronger and selective when considering the expression of each variant separately (Fig.2C): variant1 correlated with DNA methylation levels in Kappa-i2 $\left(r^{2}=0.095, p=0.0026\right.$, Fig.2D), but not in any other genomic region examined. In contrast, variant2 expression correlated with DNA methylation in Kappa-ev2 $\left(r^{2}=0.13, p=0.0005\right.$; Fig.2E), but not in other regions. Together, these results bring to light epigenetic adaptations that regulate, or reflect (42), isoform-specific transcriptional activity of the Kappa gene. 
We next searched for differential DNA methylation across C, CA and SNA groups. In the Kappa promoter, DNA methylation varied significantly among CGs $[F(9,819)=1044 ; p<0.0001]$, but there was no difference between groups $[F(2,91)=0.95$; $\mathrm{p}=0.39]$, and no interaction $[F(18,819)=1.02 ; \mathrm{p}=0.44]$ (Fig.3A-B). Looking at the Kappaev2 region, we again found a difference in methylation among CGs $[F(20,1820)=58.27$; $p<0.0001]$, but no group difference $[F(2,91)=1.685 ; \quad p=0.19]$ or interaction $[F(40,1820)=0.79 ; p=0.82]$ (Fig.3C-D). Therefore, while DNA methylation in Kappa-ev2 significantly predicts variant2 expression in our cohort (Fig.2D), there is no significant difference for either measure among groups. Furthermore, we did not find any difference in the 3 additional exons examined (Fig.S6-8), where DNA methylation was strikingly similar across groups.

In contrast, we found significantly different DNA methylation in Kappa-i2 (Fig.3E). Statistical analysis found a significant main effect of $C G s[F(10,910)=225.3 ; p<0.0001]$, as well as a significant difference between groups $[F(2,91)=4.40 ; p=0.015]$ and a significant interaction $[F(20,910)=1.59 ; p=0.048]$. Group comparisons showed that DNA methylation was lower in CA compared to SNA subjects $(p=0.011)$, while there was no difference between $C$ and SNA groups $(p=0.33)$. Tukey's post-hoc comparisons (which control for family-wise error-rate (43)) found several CG sites where CA subjects showed significantly decreased DNA methylation (Fig.3F). In particular, the most significant group differences were located in the first three CGs in Kappa-i2, where CA subjects showed decreased DNA methylation compared to both $C(p=0.047)$ and SNA $(p=0.0008)$ groups (Fig.3G). These results indicate that CA associates with decreased DNA methylation in the Kappa-i2 region in a cluster of 3 consecutive CG dinucleotides.

\section{Expression of Kappa is regulated by glucocorticoid receptor binding at the level}

\section{of intron2}


We then explored how DNA methylation in Kappa-i2 might impact Kappa expression. We cloned the corresponding 850-bp DNA sequence, and explored its promoter/enhancer potential using Luciferase assays. We first characterized the activity of Kappa-i2 in the absence of a promoter (Basic construct, Fig4A). One-way ANOVA found a significant main effect of vectors $[F(2,29)=184.4 ; p<0.001]$, while Tukey's posthoc comparisons showed that insertion of Kappa-i2 into the reporter construct potently stimulated Luciferase activity $(p<0.001)$. This effect was strongly attenuated when Kappa-i2 was patch-methylated in vitro before insertion into the vector $(\mathrm{p}<0.001)$.

We then used an EF1 $\alpha$ promoter construct to explore the enhancer activity of Kappa-i2 (Fig.4B), which may better recapitulate its intronic location in the Kappa gene. ANOVA found a significant difference between vectors $[F(2,28)=149.9 ; p<0.001]$. Tukey's comparisons showed that the addition of Kappa-i2 upstream the EF1 $\alpha$ promoter strongly potentiated Luciferase expression $(p<0.001)$. Interestingly, this stimulatory effect was attenuated when Kappa-i2 was patch-methylated $(p<0.001)$. Our results indicate that Kappa-i2 is an enhancer site that likely determines Kappa expression in vivo, an effect that is modulated by levels of DNA methylation at this locus.

Genome-wide ENCODE data recently documented binding sites for transcription factors in the Kappa-i2 region: the glucocorticoid receptor (GR), GA binding protein transcription factor alpha subunit (GABPA), hepatocyte nuclear factor 4 alpha (HNF4A) and gamma (HNF4G) (Fig.S9A). We focused on GR because we, and others, have shown that early-life adversity dysregulates GR signalling and the activity of the HPA axis (44-46). Furthermore, an extensive rodent literature indicates that activity of the dynorphin-Kappa system is potentiated by stressful experiences (4, 47-49). As such, we treated cells with DXM prior to luciferase analyses. A two-way ANOVA found significant main effects of vectors $[F(2,24)=290.4, p<0.0001]$ and of $D X M[F(1,24)=38.18$, 
$p<0.0001]$, and a significant interaction $[F(2,24)=33.67, p<0.0001]$ (Fig.4C). Tukey's comparisons indicated that in the absence of DXM, Luciferase activity was increased by Kappa-i2 $(p<0.001)$, an effect that was abolished following patch-methylation (CG-free Basic vs methylated Kappa-i2, $\mathrm{p}=0.91)$. Further, while DXM stimulation had no effect on the empty vector (CG-free Basic, p>0.99), it strongly potentiated Luciferase activity of the Kappa-i2 vector $(\mathrm{p}<0.001)$. Importantly, patch-methylation of Kappa-i2 completely blocked the effect of DXM ( $p>0.99)$. Altogether, our results demonstrate that GR binds to the Kappa-i2 enhancer to regulate Kappa expression. In addition, DNA methylation likely represents an epigenetic mechanism that modulates Kappa expression by regulating GR binding at the Kappa-i2 locus.

\section{A history of child abuse associates with decreased hydroxymethylation of Kappa intron2}

Results from Luciferase assays indicate that low levels of DNA methylation in Kappa-i2 facilitate GR binding and Kappa expression. These results appeared at odds with our in vivo findings, as CA associated with decreased DNA methylation in Kappa-i2 and decreased Kappa expression. We reasoned that the recently acknowledged distinction between two forms of DNA methylation, $5 \mathrm{mC}$ and $5 \mathrm{hmC}$, might help reconcile these observations. First, the popular bisulfite conversion method, which we used to measure DNA methylation ex vivo (Fig2-3), does not distinguish between $5 \mathrm{mC}$ and $5 \mathrm{hmC}$, as both marks are resistant to conversion. Second, recent data suggest that $5 \mathrm{mC}$ and $5 \mathrm{hmC}$ have opposite effects on transcription, inhibiting and stimulating activity, respectively (50-56). Lastly, the M.Sssl enzyme, which we and others typically use for in vitro methylation of DNA fragments, converts unmodified cytosines to $5 \mathrm{mC}$, not $5 \mathrm{hmC}(57)$. Therefore, we speculated that the lower DNA methylation observed in vivo as a function 
of CA may stem, at least in part, from decreased $5 \mathrm{hmC}$ levels, an adaptation that may account for decreased Kappa expression.

We used oxBS (28) to differentiate $5 \mathrm{mC}$ and $5 \mathrm{hmC}$ levels, and focused on the cluster of 3 CG dinucleotides that we identified in Kappa-i2. A 2-way ANOVA found significant 5mC differences among CGs $[F(2,120)=139, p<0.001]$, with group differences $[F(2,120)=14.18, p<0.001]$, but no interaction $[F(4,120)=0.2735, p=0.89]$ (Fig.5A). Tukey's comparisons showed that $5 \mathrm{mC}$ levels were increased in both $\mathrm{CA}$ $(p<0.001)$ and SNA $(p<0.001)$ subjects compared to $C$ (Fig.5B). We also found significant $5 \mathrm{hmC}$ differences between $\mathrm{CGs}[\mathrm{F}(2,120)=8.48, \mathrm{p}<0.001]$, as well as significant group differences $[F(2,120)=4.63, p=0.012]$, with no interaction $[F(4$, $120)=0.40, p=0.81$ ] (Fig.5C). Importantly, Tukey's comparisons indicated that 5hmC levels were decreased in subjects with a history of CA compared to $C(p=0.011)$, while suicide completers with no history of CA did not differ from $C$ ( $p=0.64)$ (Fig.5D). Therefore, our results indicate that CA specifically associated with decreased hydroxymethylation of Kappa-i2.

\section{Discussion}

This study was designed to address the hypothesis that severe experiences of CA might trigger long-lasting adaptations in the opioid system. Previous studies have uncovered a relationship between genetic $\mathrm{Mu}$ polymorphisms $(6,14,18,58)$ and the quality of mother-infant interactions. Also, a deficit in attachment behaviour was found in mouse pups lacking Mu receptors (7). The present study, however, failed to detect a change in Mu expression across 3 brain regions in subjects with a history of $\mathrm{CA}$, perhaps because early-life adversity may affect $\mathrm{Mu}$ in other brain structures, such as those implicated in social reinforcement and motivation (e.g. the mesolimbic pathway (59)). In contrast, we observed that abused subjects showed decreased expression of Kappa in the Al. This 
effect originated from decreased expression of Kappa variant1, while expression of variant2 was unaffected, indicating that CA differentially modulates Kappa alternative splicing. Importantly, this effect could not be accounted for by psychopathology, as suicide completers with no history of CA showed Kappa expression levels similar to controls. While a limited number of rodent studies on maternal separation $(60,61)$ or social isolation (12) reported opioid adaptations that in part affect Kappa, to our knowledge we provide the first direct evidence for an impact of early-life adversity on this opioid receptor in the human brain.

In order to identify epigenetic mechanisms potentially mediating decreased Kappa expression, we focused on DNA methylation. Over the large number of CG sites that were examined, we found that CA affected 3 CG dinucleotides in Kappa-i2, which showed lower DNA methylation levels. Next, we demonstrated that Kappa-i2 is an enhancer region where GR binds to regulate Kappa expression. These findings shed light on a new facet of the tight interactions between the opioid system and stress. Rodent studies have extensively demonstrated that increased dynorphin-Kappa signalling mediates the behavioural impact of various stressors including social defeat (62, 63), footshocks $(64,65)$ and forced swim (64, 66-69). Pharmacological and knockout studies indicate that two components of the HPA axis, GR (66) and corticotropin-releasing hormone (CRH (64)), are necessary for manifestation of these effects. Here we show that at the molecular level, stress-induced potentiation of Kappa signalling may result, at least in part, from GR binding to Kappa-i2 and increased Kappa expression. We therefore provide evidence documenting a direct interaction between GR and Kappa in human, a finding with immediate implications considering current investigations of this receptor as a therapeutic target in stress-related conditions, including depression and suicidal ideation (70-73). Finally, our results indicate that DNA methylation is an epigenetic mechanism that controls Kappa expression by modulating 
GR binding to Kappa-i2. Whether GR and epigenetic regulatory mechanisms are conserved at Kappa loci in rodent and primate species will have to be explored in future studies.

CA associated in Kappa-i2 with decreased levels of DNA methylation, as measured using a bisulfite conversion-based method. Based on our in vitro results, decreased DNA methylation at this locus would be expected to potentiate GR binding and Kappa expression. Surprisingly, decreased Kappa expression was observed in abused subjects, suggesting that a mechanism other than differential GR binding may be implicated. Accordingly, we speculated that the two most abundant cytosine modifications in mammalian brains, $5 \mathrm{mC}$ and $5 \mathrm{hmC}$, might be differentially affected by CA. We found that $5 \mathrm{mC}$ levels are increased in all suicide completers, whether they had an history of $\mathrm{CA}$ or not. In contrast, we found that $5 \mathrm{hmC}$ levels are specifically decreased in CA subjects, but not in non-abused suicide completers. Increased levels of $5 \mathrm{mC}$ are unlikely to be the primary adaptation driving decreased Kappa expression following $\mathrm{CA}$, as this modification was also present in non-abused suicide completers who did not show any change in receptor expression. Rather, considering the notion that gene body $5 \mathrm{hmC}$ positively correlates with transcriptional activity (50-55), our results suggest that decreased $5 \mathrm{hmC}$ in Kappa-i2 may drive decreased Kappa expression following CA. Whether such effects implicate the modulation of GR binding at this locus by levels of $5 \mathrm{hmC}$ remains to be determined. Ultimately, we speculate that these effects might contribute to behavioural dysregulation and psychopathology into adulthood. The role of Kappa, while thoroughly investigated in monoaminergic brainstem nuclei and frontal cortical areas in rodents $(47-49,74-76)$, remains virtually ignored so far in the insular lobe. Interestingly, the first PET-Scan study on Kappa (77) recently reported that lower availability of the receptor in the insula significantly correlated with clinical symptomatology ("loss" symptoms) in subjects with a history of traumatic life events. 
Future studies will be necessary to characterize Kappa function in the insula, a brain structure with a prominent role in social emotions (78), and how it may be disrupted following adverse experiences.

In conclusion, the present findings show that early-life adversity epigenetically programs the expression of Kappa. They also provide the first evidence, to our knowledge, that $\mathrm{CA}$ may impact the $5 \mathrm{hmC}$ epigenetic mark in the brain. Finally, they unveil a new facet of KOR physiology in human, whereby this receptor may encode social experiences during early life.

\section{Conflict of Interest}

The authors declare no conflict of interest.

\section{Acknowledgments}

We acknowledge the expert help of the DBCBB staff (Josée Prud'homme, Maâmar Bouchouka, Danielle Cécyre). PEL is supported by scholarships from the Fondation Fyssen, the Fondation Bettencourt-Schueller, the Canadian Institutes of Health Research, the American Foundation of Suicide Prevention, the Fondation Deniker and the Fondation pour la Recherche Médicale.

\section{Figure Legends}

Figure 1. The expression of the Kappa opioid receptor is decreased in the anterior insula of suicide completers with a history of severe child abuse. In the present study, we focused on 3 brain regions: (1) the anterior cingulate cortex (ACC, panel A): $\mathrm{N}=26$ psychiatrically healthy individuals (controls, C) and 26 suicide completers with a history of child abuse (CA); (2) the mediodorsal thalamus (MDT, panel B): N=27 C and $26 \mathrm{CA}$; (3) the anterior insula ( $\mathrm{Al}$, panel $\mathrm{C}$ ): $\mathrm{N}=33 \mathrm{C}$ and $30 \mathrm{CA}$. Expression of the 6 
opioid genes was quantified using RT-PCR: proopiomelanocortin (POMC), proenkephalin (Enk), prodynorphin (Dyn), mu opioid receptor (Mu), delta opioid receptor (Delta), kappa opioid receptor (Kappa). Our results indicate that a history of severe CA associated with decreased Kappa expression in the Al. Specifically, in the ACC (A), we found no difference between $\mathrm{C}$ and $\mathrm{CA}$ subjects for any opioid peptide or receptor (POMC $[F(1,51)=1.66 ; p=0.20], \quad$ Enk $[F(1,51)=2.08 ; p=0.16], \quad$ Dyn $\quad[F(1,51)=2.84 ;$ $p=0.098]$, Mu $[F(1,51)=0.00 ; p=0.99]$, Delta $[F(1,51)=0.17 ; p=0.64]$, or Kappa $[F(1,51)=0.10 ; p=0.76])$. In the MDT $(B)$, expression of Delta was nominally increased in CA subjects compared to $\mathrm{C}$, an effect that did not remain significant after Bonferroni correction (corrected $\mathrm{p}=0.20$ ), while other opioid peptides (POMC $[F(1,52)=3.47$; $\mathrm{p}=0.068]$; Enk $[F(1,52)=0.049 ; \mathrm{p}=0.83])$ and receptors $(\mathrm{Mu}[\mathrm{F}(1,52)=0.37 ; \mathrm{p}=0.55]$, Kappa $[F(1,52)=0.80 ; p=0.37])$ were unaffected. Expression of Dyn was too low (Ct values above 35, data not shown) to be accurately measured in the MDT. Finally, in the Al (C) we observed a strong and significant decrease in Kappa expression $[F(1,62)=9.73 ; p=0.00276]$ (corrected $p=0.0470$ ), with no group differences for other genes $(P O M C[F(1,62)=1.29 ; p=0.26]$, Enk $[F(1,62)=0.49 ; p=0.83]$, Dyn $[F(1,62)=0.70$; $p=0.41]$, Mu $[F(1,62)=0.042 ; p=0.84]$, Delta $[F(1,62)=0.048 ; p=0.83])$. Data are mean \pm sem. *,$p<0.05$ after Bonferroni correction.

Figure 2. Alternative splicing of the Kappa opioid receptor is selectively affected by a history of child abuse, and epigenetically regulated at distinct genomic sites. To control for possible effects of suicide and related psychopathology, we included in our analyses a third group of suicide completers with no history of abuse during childhood (SNA, N=30). (A) We quantified by RT-PCR the expression of Kappa variant1 (NM_000912.4), Kappa variant2 (NM_001282904.1), and the combined expression of both variants. (B) Results indicated that child abuse (CA) significantly associated in the 
anterior insula with decreased expression of variant $1[F(1,92)=9.64 ; p=0.003)]$, but not variant2 $[F(1,92)=2.86 ; p=0.094]$, while there was no effect of suicide on either variant. Data are mean \pm sem. ${ }^{*}, p<0.05$. (C) To explore potential epigenetic regulation of alternative splicing in the Kappa gene, we then conducted a DNA methylation analysis of 169 CG sites distributed over 7 genomic regions (shown in A), and measured linear correlations between average methylation levels in each region and the expression of Kappa variants. (D) Results indicated that levels of DNA methylation in intron2 (Kappai2) predicted the expression of variant1 (left panel), while DNA methylation in the small alternative exon specific to Kappa variant2 (Kappa-ev2) selectively correlated with expression of the corresponding isoform (right panel). In contrast, there was no significant correlation between expression of either variant and any other genomic site. Data are mean \pm sem. ${ }^{*}, \mathrm{p}<0.05$.

Figure 3. Child abuse specifically associates with differential DNA methylation in the kappa opioid receptor intron2. Differences in levels of DNA methylation were explored between psychiatrically healthy individuals (controls, $\mathrm{C}, \mathrm{N}=34$ ), suicide completers with a history of child abuse $(\mathrm{CA}, \mathrm{N}=30)$, and suicide completers without any history of abuse (SNA, N=30) in 7 genomic regions of the kappa opioid receptor (Kappa) gene. In Kappa promoter region (A-B) and in the variant2-specific exon (C-D), we found no significant difference among groups, either at the level of individual CG sites (A-C) or in the entire region (B-D, and see main text). In contrast, we found that DNA methylation levels were significantly affected across groups in the intron2 of Kappa variant1 (E-G) $[F(2,91)=4.40 ; p=0.015]$. Post-hoc comparisons found several CG sites where CA subjects showed significantly decreased DNA methylation (E): CG1, CA vs SNA $(p=0.038)$; CG2, $C$ vs CA $(p=0.029)$ and CA vs SNA ( $p=0.0024) ; C G 3$, CA vs SNA 
$(p=0.0039) ; C G 4, C A$ vs SNA ( $p=0.045)$; $C G 5$, CA vs SNA ( $p=0.023)$; $C G 8, C A$ vs SNA $(p=0.0085)$; $C G 10, C A$ vs SNA ( $p=0.031)$. Importantly, DNA methylation was particularly affected at the level of the first 3 CG sites within the targeted region (G), where CA subjects showed decreased methylation compared to both $C(p=0.047)$ and SNA $(\mathrm{p}=0.0008)$ groups. Data are mean \pm sem. ${ }^{*}, \mathrm{p}<0.05$ and ${ }^{* *}, \mathrm{p}<0.001$ between CA and SNA groups; \#, $p<0.05$ between $C$ and CA groups.

Figure 4. Expression of the Kappa opioid receptor is epigenetically regulated by glucocorticoid receptor binding at the level of its second intron. Luciferase assays were conducted to investigate potential regulation of the Kappa opioid receptor expression (Kappa) at the level of the Kappa-i2 genomic site. (A) We found that insertion of Kappa-i2 into a reporter construct strongly potentiated Luciferase activity (CpG-free Basic vs Kappa-i2; $\left.{ }^{*}, \mathrm{p}<0.001\right)$ in the neuroblastoma SK-N-AS cell line. This effect was significantly attenuated by in vitro patch-methylation of the construct (Kappa-i2 vs methylated Kappa-i2; +, $p<0.001$ ), which nevertheless still resulted in higher Luciferase activity compared to the empty vector (CpG-free Basic vs methylated Kappa-i2, $\mathrm{p}=0.018$ ). (B) Similar results were found when Kappa-i2 was inserted upstream of the EF1 $\alpha$ promoter, indicating that Kappa-i2 may act as an enhancer. (C) Finally, we characterized the effect of glucocorticoid receptor (GR) binding on Kappa-i2, using dexamethasone (DXM) stimulation as described recently(45). Although SK-N-AS cells expressed GR (data not shown), these cells appeared insensitive to DXM stimulation under our experimental conditions (Fig.S10A). Switching to HeLa cells, which are known to respond to glucocorticoids (45), we determined the lowest DXM dose necessary to achieve maximal GR effect (Fig.S10A). In addition, because DXM stimulated the EF1 $\alpha$ promoter in the absence of any DNA insert (Fig.S10B), the Basic construct was used. 
Results showed that the effect of Kappa-i2 on Luciferase activity $\left({ }^{*}, p<0.001\right.$ CpG-free Basic vs Kappa-i2, in the absence of DXM) was strongly potentiated by DXM stimulation (Kappa-i2 with vs without DXM; \#, p<0.001), indicating that GR binds to Kappa-i2 to stimulate transcriptional activity. In addition, DXM stimulation was completely prevented by patch-methylation of Kappa-i2 (methylated Kappa-i2 with vs without DXM; p>0.99), revealing an epigenetic mechanism that modulates GR binding to Kappa-i2. Data are mean \pm sem.

Figure 5. Child abuse specifically associates with decreased DNA hydroxymethylation in intron2 of the Kappa opioid receptor gene. We used oxBS(28) to measure levels of methylcytosines $(5 \mathrm{mC})$ and hydroxymethylcytosines $(5 \mathrm{hmC})$ in intron2 of the Kappa opioid receptor (Kappa), and focused on the 3 CG sites that showed evidence of epigenetic regulation by child abuse (CA, see Fig.3). (A-B) Results showed that $5 \mathrm{mC}$ levels were increased in anterior insula DNA from suicide completers with (CA) or without (SNA) a history of abuse. (C-D) Importantly, we found that $5 \mathrm{hmC}$ levels were specifically decreased in CA ( $p=0.011)$, but not in SNA, subjects. While accumulating evidence indicates that $5 \mathrm{hmC}$ positively regulates transcription(5055), our results suggest a model whereby decreased hydroxymethylation in Kappa intron 2 may account for persistent downregulation of the kappa opioid receptor following a history of CA. Data are mean \pm sem. +, Two-way ANOVA main group effects, $p<0.05 .{ }^{*}$, Tukey's post-hoc comparisons. 


\section{References}

1. Meyer-Lindenberg A, Tost H (2012): Neural mechanisms of social risk for psychiatric disorders. Nat Neurosci. 15:663-668.

2. Eisenberger NI (2013): Social ties and health: a social neuroscience perspective. Curr Opin Neurobiol.

3. Panksepp JB, Lahvis GP (2011): Rodent empathy and affective neuroscience. Neurosci Biobehav Rev. 35:1864-1875.

4. Lutz PE, Kieffer BL (2013): Opioid receptors: distinct roles in mood disorders. Trends Neurosci. 36:195-206.

5. Panksepp J, Panksepp JB (2013): Toward a cross-species understanding of empathy. Trends Neurosci. 36:489-496.

6. Barr CS, Schwandt ML, Lindell SG, Higley JD, Maestripieri D, Goldman D, et al. (2008): Variation at the mu-opioid receptor gene (OPRM1) influences attachment behavior in infant primates. Proc Natl Acad Sci U S A. 105:5277-5281.

7. Moles A, Kieffer BL, D'Amato FR (2004): Deficit in attachment behavior in mice lacking the mu-opioid receptor gene. Science. 304:1983-1986.

8. Trezza V, Baarendse PJ, Vanderschuren LJ (2010): The pleasures of play: pharmacological insights into social reward mechanisms. Trends Pharmacol Sci. 31:463469.

9. Cole SL, Hofford RS, Evert DJ, Wellman PJ, Eitan S (2013): Social influences on morphine conditioned place preference in adolescent mice. Addict Biol. 18:274-285.

10. Kennedy BC, Panksepp JB, Runckel PA, Lahvis GP (2012): Social influences on morphine-conditioned place preference in adolescent BALB/CJ and C57BL/6J mice. Psychopharmacology (Berl). 219:923-932.

11. Briand LA, Hilario M, Dow HC, Brodkin ES, Blendy JA, Berton O (2015): Mouse Model of OPRM1 (A118G) Polymorphism Increases Sociability and Dominance and Confers Resilience to Social Defeat. J Neurosci. 35:3582-3590.

12. Karkhanis AN, Rose JH, Weiner JL, Jones SR (2016): Early-Life Social Isolation Stress Increases Kappa Opioid Receptor Responsiveness and Downregulates the Dopamine System. Neuropsychopharmacology.

13. Resendez SL, Kuhnmuench M, Krzywosinski T, Aragona BJ (2012): kappaOpioid Receptors within the Nucleus Accumbens Shell Mediate Pair Bond Maintenance. $J$ Neurosci. 32:6771-6784.

14. Higham JP, Barr CS, Hoffman CL, Mandalaywala TM, Parker KJ, Maestripieri D (2011): Mu-opioid receptor (OPRM1) variation, oxytocin levels and maternal attachment in free-ranging rhesus macaques Macaca mulatta. Behav Neurosci. 125:131-136.

15. Hsu DT, Sanford BJ, Meyers KK, Love TM, Hazlett KE, Walker SJ, et al. (2015): It still hurts: altered endogenous opioid activity in the brain during social rejection and acceptance in major depressive disorder. Mol Psychiatry.

16. Hsu DT, Sanford BJ, Meyers KK, Love TM, Hazlett KE, Wang H, et al. (2013): Response of the mu-opioid system to social rejection and acceptance. Mol Psychiatry.

17. Inagaki TK, Ray LA, Irwin MR, Way BM, Eisenberger NI (2016): Opioids and social bonding: Naltrexone reduces feelings of social connection. Soc Cogn Affect Neurosci.

18. Way BM, Taylor SE, Eisenberger NI (2009): Variation in the mu-opioid receptor gene (OPRM1) is associated with dispositional and neural sensitivity to social rejection. Proc Natl Acad Sci U S A. 106:15079-15084.

19. Cole PM, Michel MK, Teti LO (1994): The development of emotion regulation and dysregulation: a clinical perspective. Monogr Soc Res Child Dev. 59:73-100. 
20. Heller AS, Casey BJ (2016): The neurodynamics of emotion: delineating typical and atypical emotional processes during adolescence. Dev Sci. 19:3-18.

21. Teicher MH, Samson JA (2016): Annual Research Review: Enduring neurobiological effects of childhood abuse and neglect. $J$ Child Psychol Psychiatry. 57:241-266.

22. Green JG, McLaughlin KA, Berglund PA, Gruber MJ, Sampson NA, Zaslavsky AM, et al. (2010): Childhood adversities and adult psychiatric disorders in the national comorbidity survey replication I: associations with first onset of DSM-IV disorders. Arch Gen Psychiatry. 67:113-123.

23. Gilbert R, Widom CS, Browne K, Fergusson D, Webb E, Janson S (2009): Burden and consequences of child maltreatment in high-income countries. Lancet. 373:68-81.

24. Nemeroff CB (2016): Paradise Lost: The Neurobiological and Clinical Consequences of Child Abuse and Neglect. Neuron. 89:892-909.

25. Meaney MJ, Szyf M (2005): Maternal care as a model for experience-dependent chromatin plasticity? Trends Neurosci. 28:456-463.

26. Lutz PE, Turecki G (2014): DNA methylation and childhood maltreatment: from animal models to human studies. Neuroscience. 264:142-156.

27. Wei LN, Loh HH (2011): Transcriptional and epigenetic regulation of opioid receptor genes: present and future. Annual review of pharmacology and toxicology. 51:75-97.

28. Booth MJ, Branco MR, Ficz G, Oxley D, Krueger F, Reik W, et al. (2012): Quantitative Sequencing of 5-Methylcytosine and 5-Hydroxymethylcytosine at SingleBase Resolution. Science.

29. Dumais A, Lesage AD, Alda M, Rouleau G, Dumont M, Chawky N, et al. (2005): Risk factors for suicide completion in major depression: a case-control study of impulsive and aggressive behaviors in men. Am J Psychiatry. 162:2116-2124.

30. Brewin CR, Andrews B, Gotlib IH (1993): Psychopathology and early experience: a reappraisal of retrospective reports. Psychol Bull. 113:82-98.

31. Conner KR, Conwell Y, Duberstein PR (2001): The validity of proxy-based data in suicide research: a study of patients 50 years of age and older who attempted suicide. II. Life events, social support and suicidal behavior. Acta Psychiatr Scand. 104:452-457.

32. Hawton K, Appleby L, Platt S, Foster T, Cooper J, Malmberg A, et al. (1998): The psychological autopsy approach to studying suicide: a review of methodological issues. J Affect Disord. 50:269-276.

33. Kelly TM, Mann JJ (1996): Validity of DSM-III-R diagnosis by psychological autopsy: a comparison with clinician ante-mortem diagnosis. Acta Psychiatr Scand. 94:337-343.

34. McGirr A, Tousignant M, Routhier D, Pouliot L, Chawky N, Margolese HC, et al. (2006): Risk factors for completed suicide in schizophrenia and other chronic psychotic disorders: a case-control study. Schizophr Res. 84:132-143.

35. Brent DA, Perper JA, Moritz G, Allman CJ, Roth C, Schweers J, et al. (1993): The validity of diagnoses obtained through the psychological autopsy procedure in adolescent suicide victims: use of family history. Acta Psychiatr Scand. 87:118-122.

36. Bifulco A, Brown GW, Harris TO (1994): Childhood Experience of Care and Abuse (CECA): a retrospective interview measure. J Child Psychol Psychiatry. 35:14191435.

37. Bifulco A, Brown GW, Lillie A, Jarvis J (1997): Memories of childhood neglect and abuse: corroboration in a series of sisters. J Child Psychol Psychiatry. 38:365-374. 
38. Lutz PE, Zhou Y, Labbe A, Mechawar N, Turecki G (2015): Decreased expression of nociceptin/orphanin FQ in the dorsal anterior cingulate cortex of suicides. Eur Neuropsychopharmacol.

39. Masser DR, Berg AS, Freeman WM (2013): Focused, high accuracy 5methylcytosine quantitation with base resolution by benchtop next-generation sequencing. Epigenetics Chromatin. 6:33.

40. Feng J, Shao N, Szulwach KE, Vialou V, Huynh J, Zhong C, et al. (2015): Role of Tet1 and 5-hydroxymethylcytosine in cocaine action. Nat Neurosci.

41. Chen GG, Gross JA, Lutz PE, Vaillancourt K, Maussion G, Bramoulle A, et al. (2017): Medium throughput bisulfite sequencing for accurate detection of 5methylcytosine and 5-hydroxymethylcytosine. BMC Genomics. 18:96.

42. Lev Maor G, Yearim A, Ast G (2015): The alternative role of DNA methylation in splicing regulation. Trends Genet. 31:274-280.

43. Tukey JW (1949): Comparing individual means in the analysis of variance. Biometrics. 5:99-114.

44. McGowan PO, Sasaki A, D'Alessio AC, Dymov S, Labonte B, Szyf M, et al. (2009): Epigenetic regulation of the glucocorticoid receptor in human brain associates with childhood abuse. Nat Neurosci. 12:342-348.

45. Klengel T, Mehta D, Anacker C, Rex-Haffner M, Pruessner JC, Pariante CM, et al. (2013): Allele-specific FKBP5 DNA demethylation mediates gene-childhood trauma interactions. Nat Neurosci. 16:33-41.

46. Turecki G, Meaney MJ (2014): Effects of the Social Environment and Stress on Glucocorticoid Receptor Gene Methylation: A Systematic Review. Biol Psychiatry.

47. Lalanne L, Ayranci G, Kieffer BL, Lutz PE (2014): The kappa opioid receptor: from addiction to depression, and back. Front Psychiatry. 5:170.

48. Bruchas MR, Land BB, Chavkin C (2010): The dynorphin/kappa opioid system as a modulator of stress-induced and pro-addictive behaviors. Brain Res. 1314:44-55.

49. Knoll AT, Carlezon WA, Jr. (2010): Dynorphin, stress, and depression. Brain Res. 1314:56-73.

50. Mellen M, Ayata P, Dewell S, Kriaucionis S, Heintz N (2012): MeCP2 Binds to $5 \mathrm{hmC}$ Enriched within Active Genes and Accessible Chromatin in the Nervous System. Cell. 151:1417-1430.

51. Gross JA, Pacis A, Chen GG, Barreiro LB, Ernst C, Turecki G (2015): Characterizing 5-hydroxymethylcytosine in human prefrontal cortex at single base resolution. BMC Genomics. 16:672.

52. Lister R, Mukamel EA, Nery JR, Urich M, Puddifoot CA, Johnson ND, et al. (2013): Global epigenomic reconfiguration during mammalian brain development. Science. 341:1237905.

53. Mo A, Mukamel EA, Davis FP, Luo C, Henry GL, Picard S, et al. (2015): Epigenomic Signatures of Neuronal Diversity in the Mammalian Brain. Neuron. 86:13691384.

54. Wen L, Li X, Yan L, Tan Y, Li R, Zhao Y, et al. (2014): Whole-genome analysis of 5-hydroxymethylcytosine and 5-methylcytosine at base resolution in the human brain. Genome Biol. 15:R49.

55. Pacis A, Tailleux L, Morin AM, Lambourne J, Maclsaac JL, Yotova V, et al. (2015): Bacterial infection remodels the DNA methylation landscape of human dendritic cells. Genome Res. 25:1801-1811.

56. Guo JU, Su Y, Zhong C, Ming GL, Song H (2011): Hydroxylation of 5methylcytosine by TET1 promotes active DNA demethylation in the adult brain. Cell. 145:423-434. 
57. Yu M, Hon GC, Szulwach KE, Song CX, Zhang L, Kim A, et al. (2012): Baseresolution analysis of 5-hydroxymethylcytosine in the mammalian genome. Cell. 149:1368-1380.

58. Copeland WE, Sun H, Costello EJ, Angold A, Heilig MA, Barr CS (2011): Child mu-opioid receptor gene variant influences parent-child relations. Neuropsychopharmacology. 36:1165-1170.

59. Resendez SL, Aragona BJ (2013): Aversive motivation and the maintenance of monogamous pair bonding. Rev Neurosci. 24:51-60.

60. Ploj K, Nylander I (2003): Long-term effects on brain opioid and opioid receptor like-1 receptors after short periods of maternal separation in rats. Neurosci Lett. 345:195-197.

61. Ploj K, Roman E, Nylander I (2003): Long-term effects of maternal separation on ethanol intake and brain opioid and dopamine receptors in male Wistar rats. Neuroscience. 121:787-799.

62. Bruchas MR, Schindler AG, Shankar H, Messinger DI, Miyatake M, Land BB, et al. (2011): Selective p38alpha MAPK Deletion in Serotonergic Neurons Produces Stress Resilience in Models of Depression and Addiction. Neuron. 71:498-511.

63. McLaughlin JP, Li S, Valdez J, Chavkin TA, Chavkin C (2006): Social defeat stress-induced behavioral responses are mediated by the endogenous kappa opioid system. Neuropsychopharmacology. 31:1241-1248.

64. Land BB, Bruchas MR, Lemos JC, Xu M, Melief EJ, Chavkin C (2008): The dysphoric component of stress is encoded by activation of the dynorphin kappa-opioid system. J Neurosci. 28:407-414.

65. Beardsley PM, Howard JL, Shelton KL, Carroll FI (2005): Differential effects of the novel kappa opioid receptor antagonist, JDTic, on reinstatement of cocaine-seeking induced by footshock stressors vs cocaine primes and its antidepressant-like effects in rats. Psychopharmacology (Berl). 183:118-126.

66. Polter AM, Bishop RA, Briand LA, Graziane NM, Pierce RC, Kauer JA (2014): Poststress Block of Kappa Opioid Receptors Rescues Long-Term Potentiation of Inhibitory Synapses and Prevents Reinstatement of Cocaine Seeking. Biol Psychiatry.

67. Flaisher-Grinberg S, Persaud SD, Loh HH, Wei LN (2012): Stress-induced epigenetic regulation of kappa-opioid receptor gene involves transcription factor c-Myc. Proc Natl Acad Sci U S A. 109:9167-9172.

68. Falcon E, Maier K, Robinson SA, Hill-Smith TE, Lucki I (2014): Effects of buprenorphine on behavioral tests for antidepressant and anxiolytic drugs in mice. Psychopharmacology (Berl).

69. Huang P, Tunis J, Parry C, Tallarida R, Liu-Chen LY (2016): Synergistic antidepressant-like effects between a kappa opioid antagonist (LY2444296) and a delta opioid agonist (ADL5859) in the mouse forced swim test. Eur J Pharmacol. 781:53-59.

70. Yovell Y, Bar G, Mashiah M, Baruch Y, Briskman I, Asherov J, et al. (2015): Ultra-Low-Dose Buprenorphine as a Time-Limited Treatment for Severe Suicidal Ideation: A Randomized Controlled Trial. Am J Psychiatry.appiajp201515040535.

71. Harrison C (2013): Trial watch: Opioid receptor blocker shows promise in Phase II depression trial. Nat Rev Drug Discov. 12:415.

72. Ehrich E, Turncliff R, Du Y, Leigh-Pemberton R, Fernandez E, Jones R, et al. (2015): Evaluation of opioid modulation in major depressive disorder. Neuropsychopharmacology. 40:1448-1455.

73. Falcon E, Browne CA, Leon RM, Fleites VC, Sweeney R, Kirby LG, et al. (2016): Antidepressant-like Effects of Buprenorphine are Mediated by Kappa Opioid Receptors. Neuropsychopharmacology. 
74. Wee S, Koob GF (2010): The role of the dynorphin-kappa opioid system in the reinforcing effects of drugs of abuse. Psychopharmacology (Berl). 210:121-135.

75. Kreek MJ, Zhou Y, Butelman ER, Levran O (2009): Opiate and cocaine addiction: from bench to clinic and back to the bench. Curr Opin Pharmacol. 9:74-80.

76. Muschamp JW, Hollander JA, Thompson JL, Voren G, Hassinger LC, Onvani S, et al. (2014): Hypocretin (orexin) facilitates reward by attenuating the antireward effects of its cotransmitter dynorphin in ventral tegmental area. Proc Natl Acad Sci $U S A$. 111:E1648-1655.

77. Pietrzak $\mathrm{RH}$, Naganawa M, Huang Y, Corsi-Travali S, Zheng MQ, Stein MB, et al. (2014): Association of In Vivo kappa-Opioid Receptor Availability and the Transdiagnostic Dimensional Expression of Trauma-Related Psychopathology. JAMA Psychiatry.

78. Lamm C, Singer T (2010): The role of anterior insular cortex in social emotions. Brain Struct Funct. 214:579-591. 
A) Anterior Cingulate cortex POMC Enk

Dyn

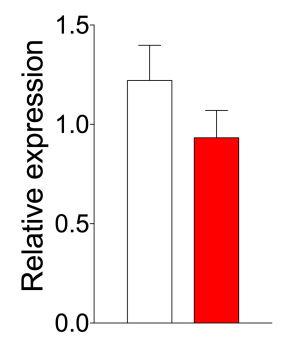

$\mathrm{Mu}$

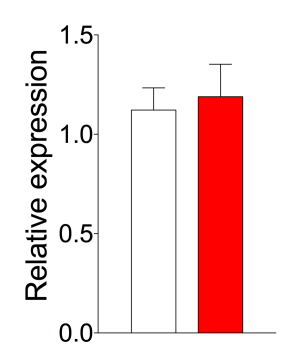

C) Anterior Insula
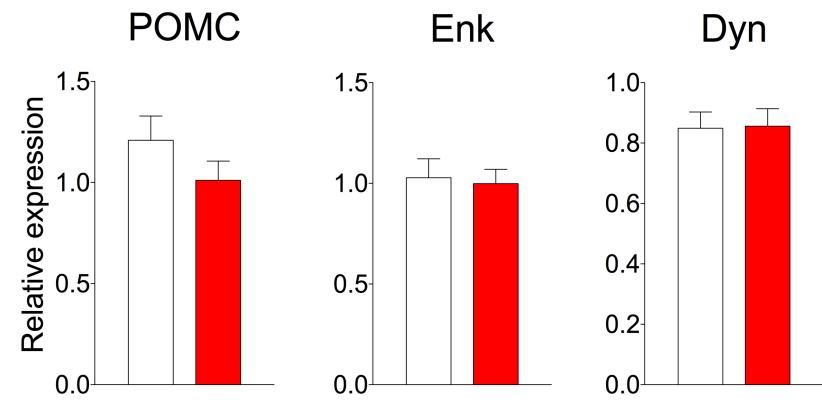

$\mathrm{Mu}$
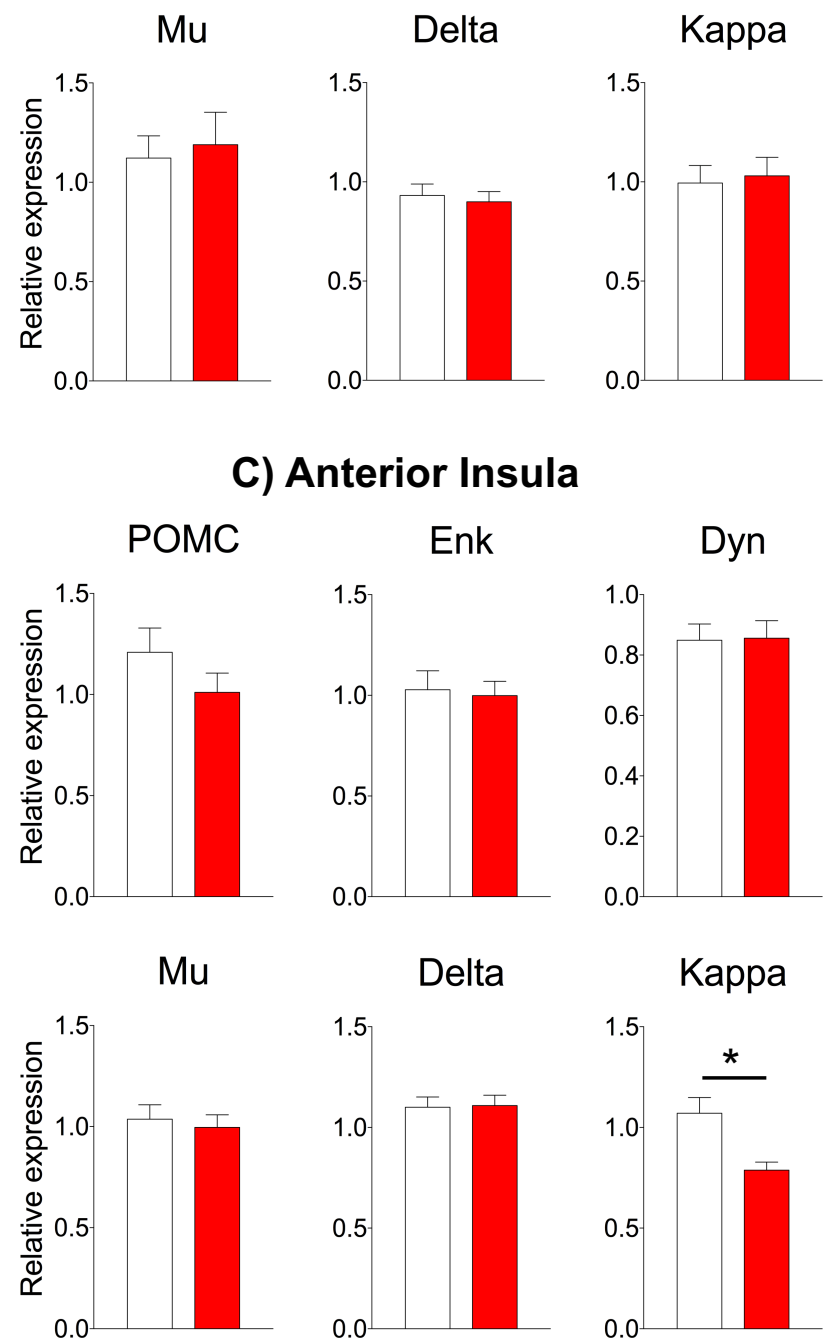

B) Medio-Dorsal Thalamus

POMC

Enk
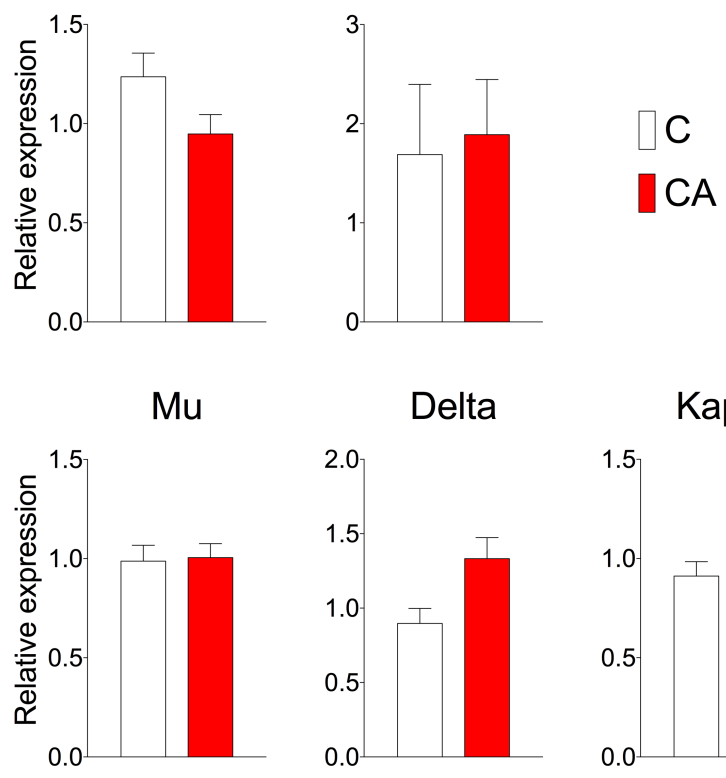

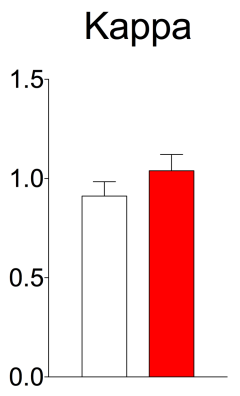

Fig1. 
A)

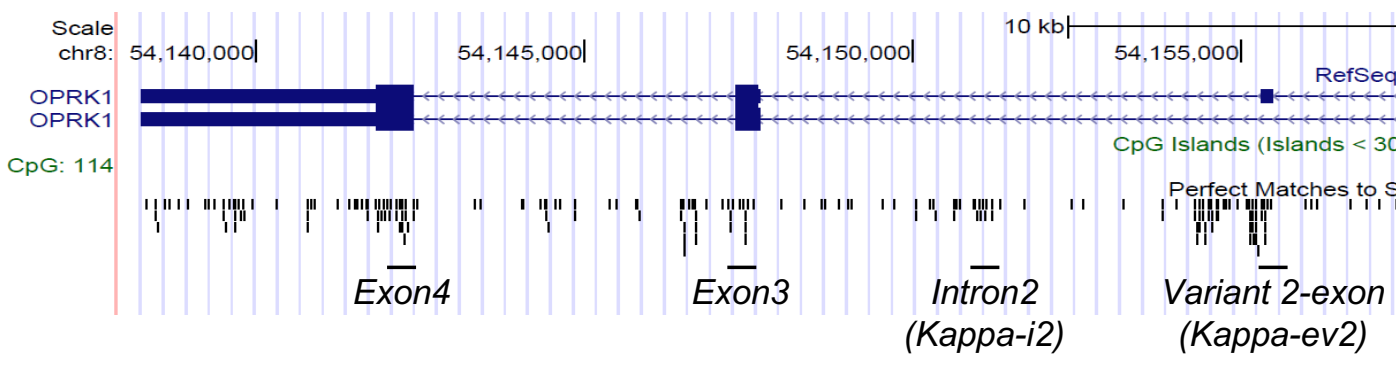

B)

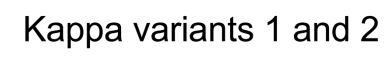

Kappa variant 1

Kappa variant 2
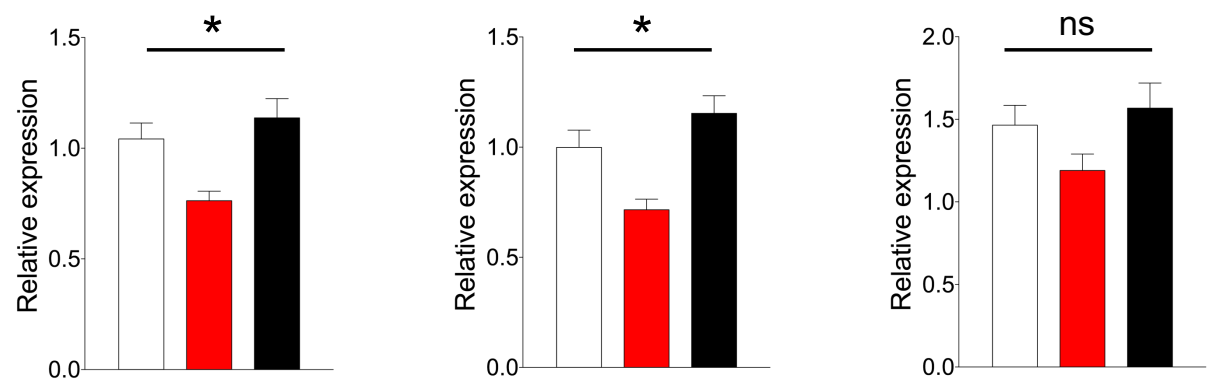

$\square \mathrm{C}$

ICA

ISNA

C)

\begin{tabular}{|c|c|c|c|c|c|c|c|}
\hline & Exon4 & Exon 3 & Intron 2 & $\begin{array}{c}\text { Variant2- } \\
\text { exon }\end{array}$ & Exon2 & Exon1 & Promoter \\
\hline Variants 1 and 2 & 0,93 & 0,29 & $0,0468^{*}$ & $0,0469^{*}$ & 0,84 & 0,56 & 0,94 \\
\hline Variant 1 & 0,33 & 0,16 & $0,0026^{*}$ & 0,20 & 0,57 & 0,61 & 0,92 \\
\hline Variant 2 & 0,23 & 0,77 & 0,6134 & $0,0005^{*}$ & 0,21 & 0,88 & 0,25 \\
\hline
\end{tabular}

D)
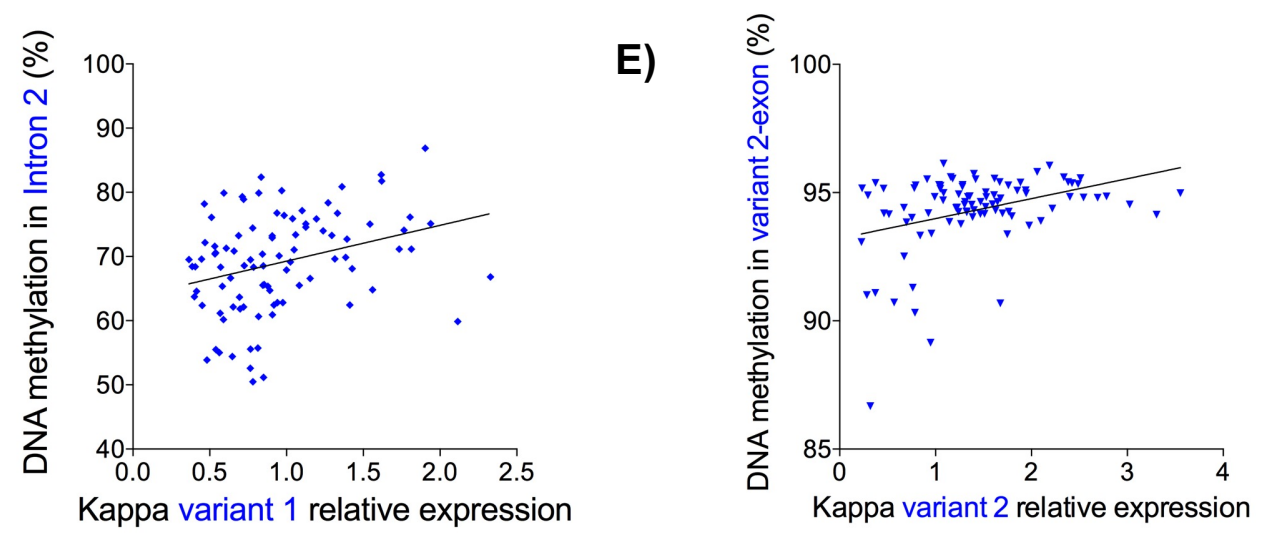
A)

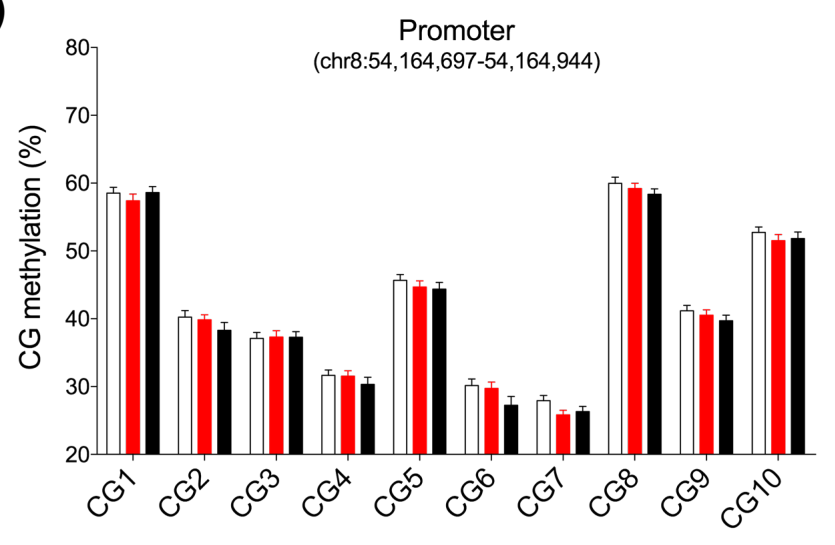

C)
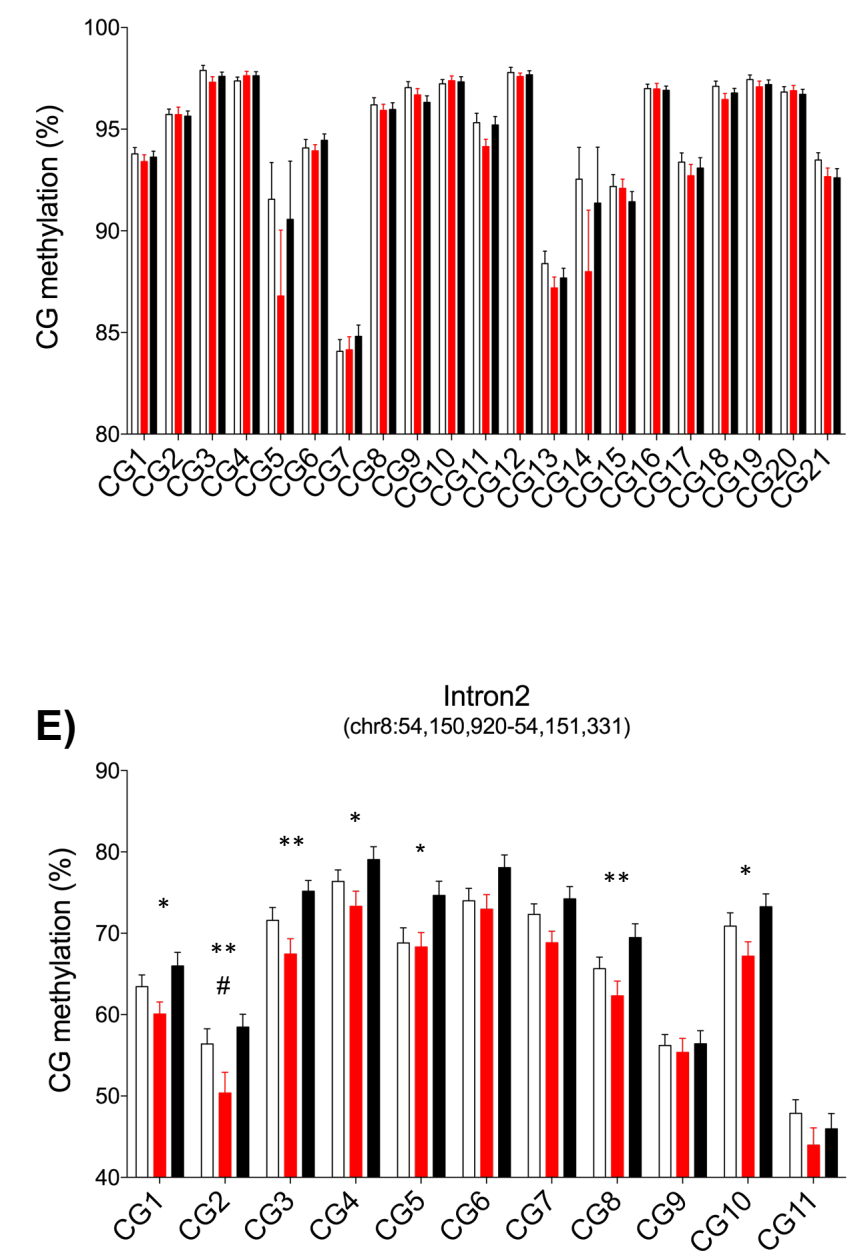

B) 10 CG sites in Promoter

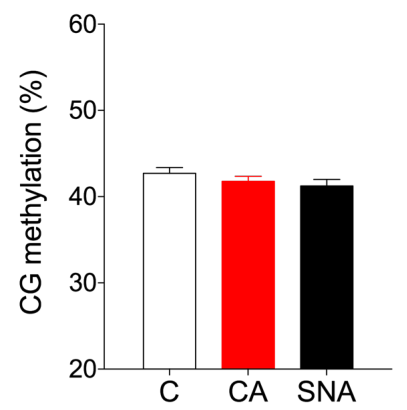

D) 21 CG sites in Intron2

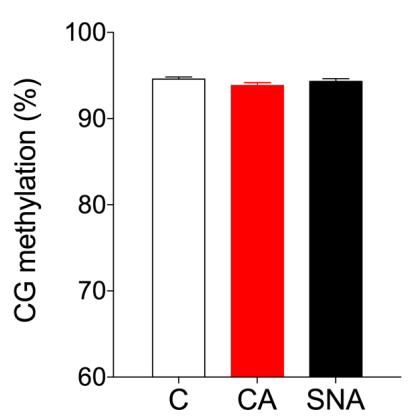

F)

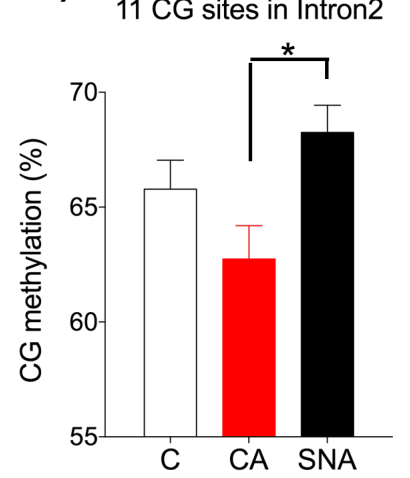

G) First 3 CG sites in Intron2

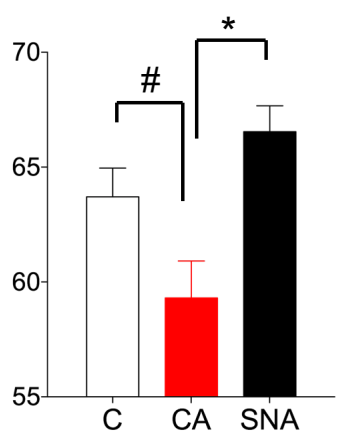


A)

$\begin{array}{cc}\text { Kappa } & \text { CpG free } \\ \text { Intron } 2 & \text { Luciferase }\end{array}$

B)

Kappa Intron 2 $C p G$ free Luciferase

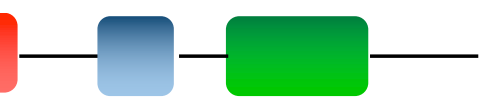

CpG-free EF1a Promoter

C)

+ Dexamethasone $50 \mathrm{nM}$

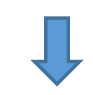

\section{Kappa} Intron 2 $C p G$ free Luciferase
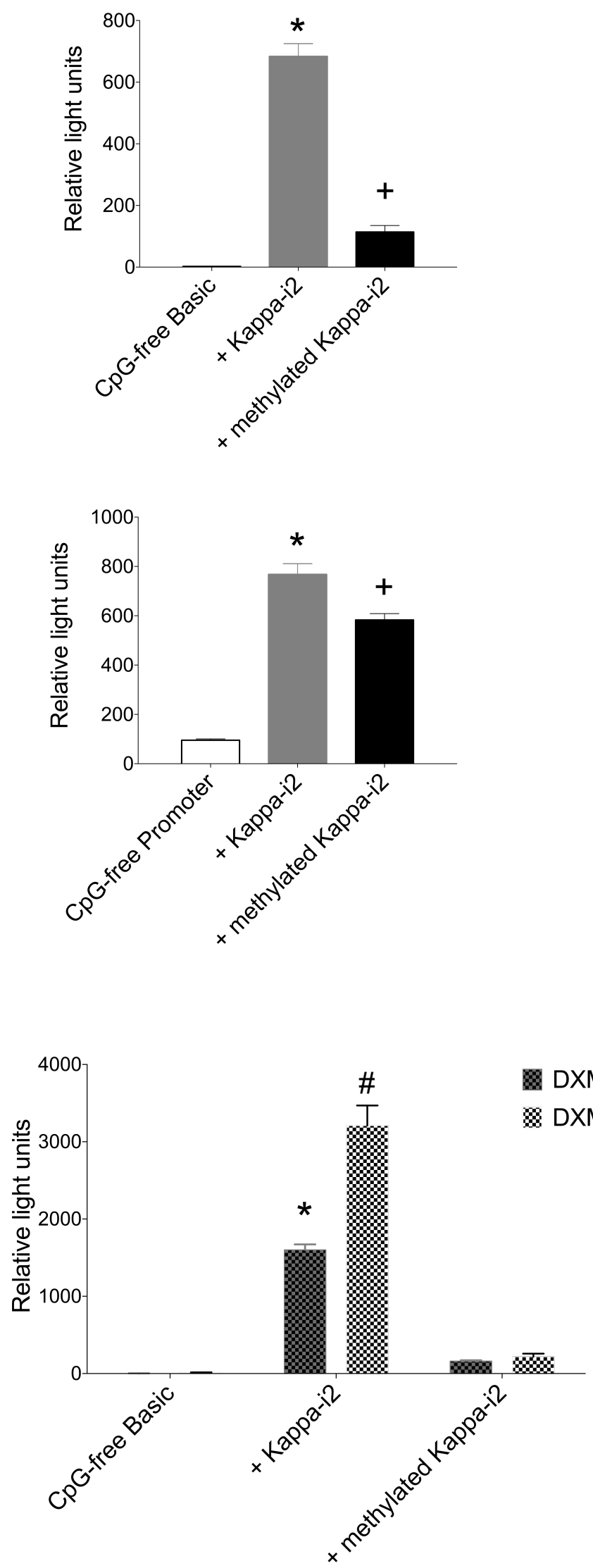
A) $\quad$ (chr8:54,151,166-54,151,365)

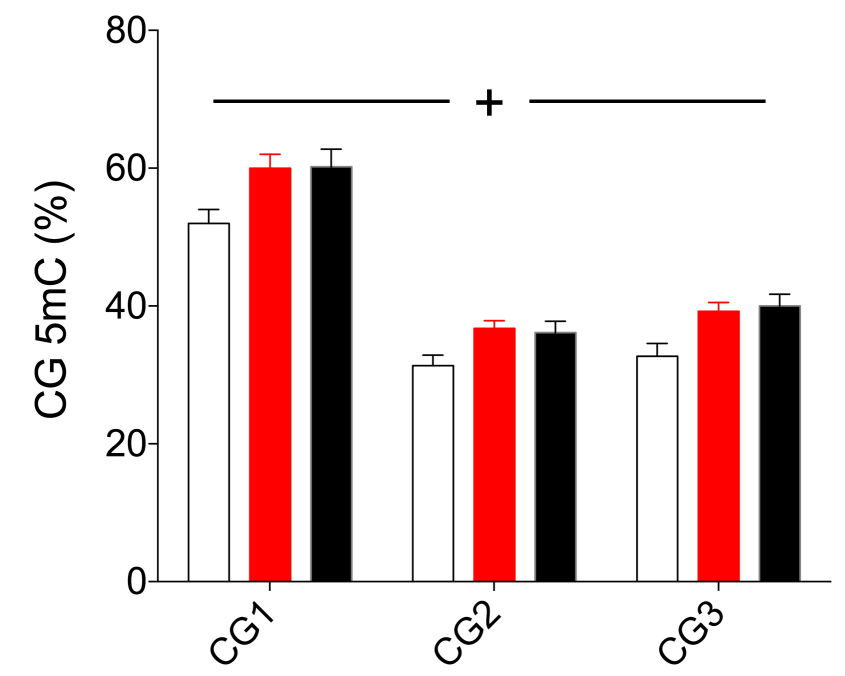

$5 \mathrm{hmC}$ in Intron2

C)

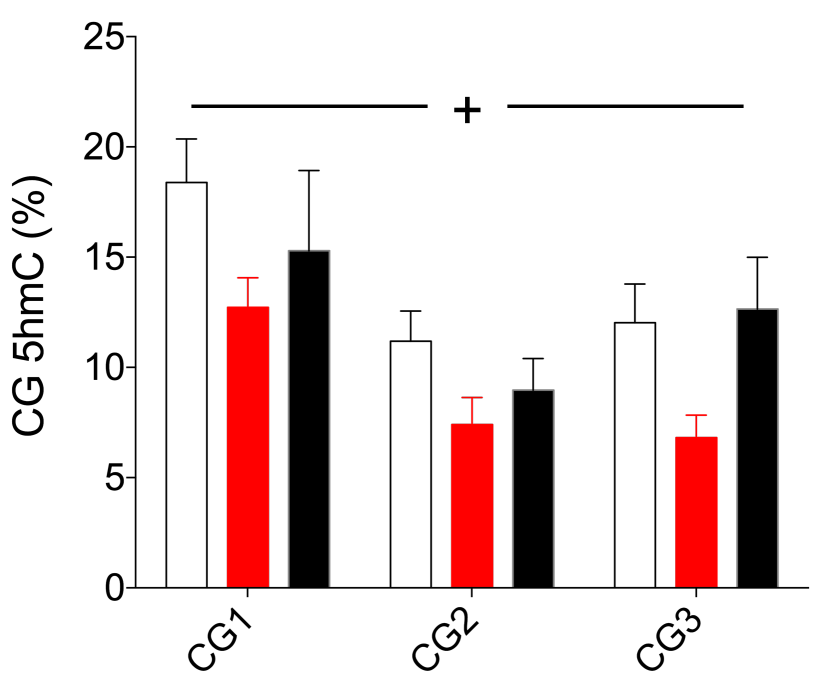

B) Mean $5 \mathrm{mC}$ in $3 \mathrm{CG}$ sites (Intron2)

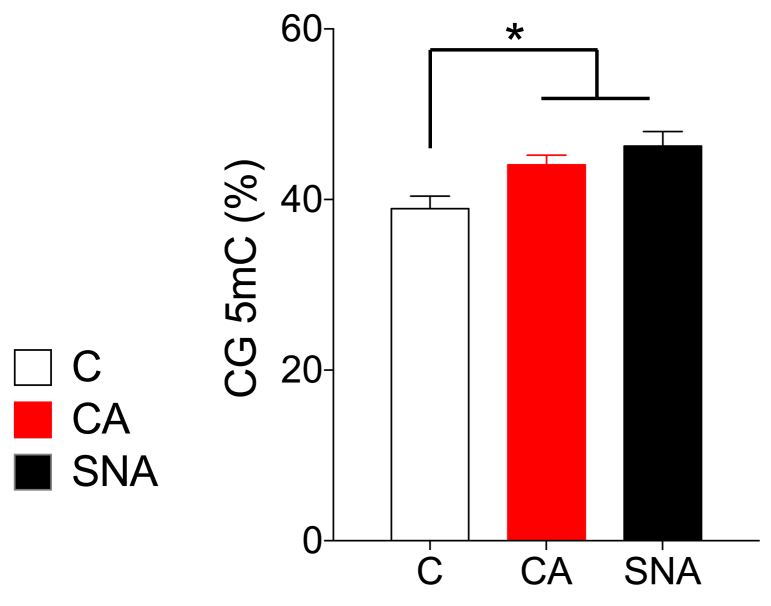

D) Mean $5 \mathrm{hmC}$ in $3 \mathrm{CG}$ sites (Intron2)

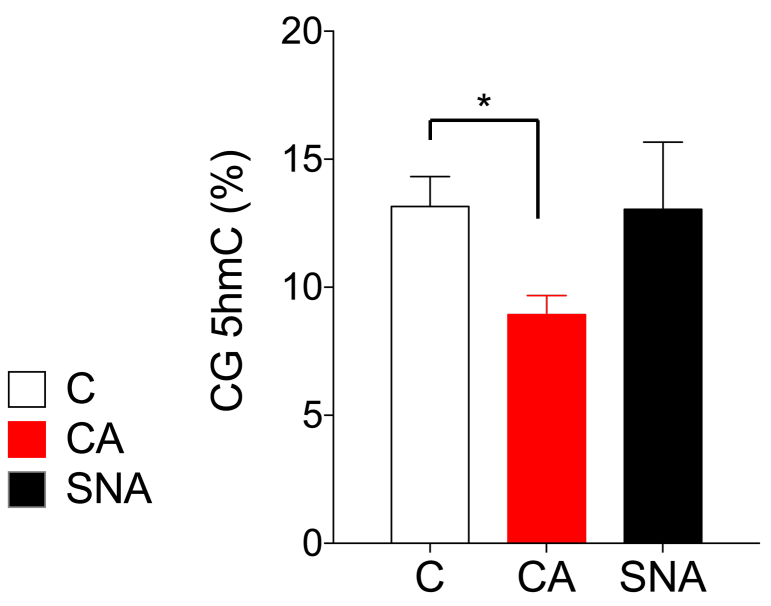

Fig5. 
Epigenetic regulation of the kappa opioid receptor by child abuse

Pierre-Eric Lutz ${ }^{1}$, Jeffrey A. Gross ${ }^{1}$, Sabine K. Dhir ${ }^{2}$, Gilles Maussion${ }^{1}$, Jennie Yang${ }^{1}$,

Alexandre Bramoulle ${ }^{1}$, Gary G. Chen ${ }^{1}$, Michael J. Meaney ${ }^{2}$, and Gustavo Turecki ${ }^{1}$

${ }^{1}$ McGill Group for Suicide Studies, Douglas Mental Health University Institute, McGill

University, 6875 LaSalle Boulevard, Verdun, Quebec, Canada, H4H 1R3

2Douglas Mental Health University Institute, McGill University, 6875 LaSalle Boulevard,

Verdun, Quebec, Canada, H4H 1R3

\section{Supplementary Material}

\section{Contents}
A. Supplementary Material and Methods
B. Legends of Supplementary Figures
C. Supplementary Figures
D. Supplementary Tables 


\section{A. Supplementary Material and Methods \\ Brain tissue dissections}

Samples of the three brain regions (dACC, MDT and Al) were dissected from each subject from $0.5 \mathrm{~cm}$-thick coronal brain sections by expert brain bank staff following standard dissection procedures and with the aid of a human brain atlas (see(1) and http://www.thehumanbrain.info/brain/bn brain atlas/brain.html). For the $\mathrm{Al}$, the superior part of the insula was dissected just beneath the overlying opercula in the brain section containing the striatum at the level of nucleus accumbens. MDT samples were obtained by dissecting the dorsal part of the thalamus ( $1 / 3$ upper part of thalamus), medially to the internal medullary lamina found in sections equivalent to plates 40 to 43 of the atlas (23.9 to $27.8 \mathrm{~mm}$ from the center of the anterior commissure). Finally, the ACC (corresponding to Brodmann area 24 and 32) was dissected in sections equivalent to plates 15 to 28 of the atlas (-7.5 to $8.0 \mathrm{~mm}$ from the center of the anterior commissure), and grey matter was taken immediately dorsal to the corpus callosum.

\section{Quantification of Gene Expression Using Reverse-Transcriptase Polymerase Chain Reaction}

We quantified the expression of the 6 genes of the opioid system, which encode for (i) opioid receptors: OPRM1 (encoding Mu), OPRD1 (delta opioid receptor, Delta), OPRK1 (Kappa opioid receptor, Kappa), and (ii) opioid peptides: POMC (encoding endorphins), PENK (enkephalins, Enk), and PDYN (dynorphins, Dyn). RNA was extracted from homogenized brain tissue samples using the RNeasy Lipid Tissue Mini Kit (Qiagen). RNA quantity and quality were measured by Nanodrop $\AA^{\circledR}$ and Agilent 2100 Bioanalyzer technologies, and only samples with a RNA integrity number (RIN) greater than 5 were

used. Extracted RNA was reverse-transcribed using M-MLV reverse transcriptase (Invitrogen ${ }^{\mathrm{TM}}$ ). mRNA levels were quantified by real time polymerase chain reaction (RT- 
PCR) using SYBR $\circledast$ Green DNA intercalating dye and master mix (Bio-Rad) and the ABI 7900HT PCR machine. Primers for targeted genes were designed using Primer-BLAST (http://www.ncbi.nlm.nih.gov/tools/primer-blast/) and validated by gel migration and dissociation curves (see Supplementary Table 2 for primers sequences). Complementary DNAs (cDNA) from every subject were pooled and used to prepare calibration curves, from which cDNA quantities of target genes were calculated in each sample according to the measured RT-PCR threshold cycle (Ct value), in quintuplicates. Relative expression levels for each gene of interest were calculated by dividing the cDNA quantity for the gene of interest by the arithmetic mean of cDNA quantities for two reference housekeeping genes (GAPDH, glyceraldehyde-3-phosphate dehydrogenase; and $\beta$-actin, actin, beta). Control experiments (using Nanostring technology, see below) were conducted to confirm that, when compared with 3 additional control genes (GUSB, glucuronidase, beta; RPL13, ribosomal protein L13; and TUBB, tubulin beta class I), expression of these 2 reference genes, GAPDH and $\beta$-actin, is stable across C, SA and SNA groups (see Fig.S2).

\section{Quantification of Gene Expression Using Nanostring}

Nanostring experiments were performed as described previously $(2,3)$ at the Jewish General Hospital Molecular Pathology Centre (Montréal, QC, Canada) using Nanostring nCounter targeted gene expression profiling (4). Briefly, $5 \mu$ of total RNA ( $20 \mathrm{ng} / \mu \mathrm{l})$ was hybridized with the reporter and capture probes at $65^{\circ} \mathrm{C}$ in a thermocycler for $19-20$ hours. Probes were designed against GAPDH and $\beta$-actin, and 3 housekeeping control genes: GUSB, RPL13, TUBB. The samples were processed with the nCounter Prep Station to purify the hybridized targets and affix them to the cartridge. After transfer to the nCounter Digital Analyzer, barcodes were counted and tabulated for each target 
molecule. The data were analyzed using the nSolver version 2.6 .43 following the manufacturer's recommendations.

\section{DNA Methylation Analysis (NEXTERA XT)}

DNA was extracted from brain tissue using the QIAamp DNA Mini Kit (QIAGEN). A NanoDrop 2000 spectrophotometer was used to assess the DNA quality and concentration. Then, we performed a DNA methylation analysis using a targeted bisulfite-sequencing approach, based on the methodology described by Masser et al(5). Briefly, genomic DNA was bisulfate converted using the EpiTect Fast Bisulfite Conversion Kit (QIAGEN), and PCR amplified using the Kapa HIFI Uracil+ mastermix. Primers for the amplification of bisulfate-converted DNA (BS-DNA) were designed using the MethylPrimer Express software v1.0 (ThermoFischer Scientific). Primer sequences can be found in Supplementary Table 3. BS-DNA was amplified by PCR on a regular thermocycler (ProFlex) with the following parameters: (1) $95^{\circ} \mathrm{C}$ for $3 \mathrm{~min}$, (2) $\left[98^{\circ} \mathrm{C}\right.$ for 20 sec - annealing temp for $15 \mathrm{sec}-72^{\circ} \mathrm{C}$ for $15 \mathrm{sec}$ ] $\times 45-50$ cycles, (3) $72^{\circ} \mathrm{C}$ for $1 \mathrm{~min}$, and hold at $4{ }^{\circ} \mathrm{C}$. The annealing temperature was set between 57 and $60^{\circ} \mathrm{C}$ depending on the primer pair used. Next, PCR amplicons were purified (to get rid of primer dimers and PCR reagents) using AMPure Beads at a 1x concentration (Agencourt). Purified PCR amplicons were then quantified, pooled and diluted to a final $0.2 \mathrm{ng} / \mu \mathrm{l}$ DNA concentration, using the Quant-iT'TM PicoGreen ${ }^{\circledR}$ dsDNA Assay Kit (ThermoFischer Scientific). Libraires were prepared using the NEXTERA XT kit (Illumina) following the manufacturer's recommandations. Briefly, for each subject, $1 \mathrm{ng}$ of DNA corresponding to the pool of purified PCR amplicons was used as starting material for tagmentation, i.e. enzymatic digestion and tagging by transposases. "Tagmented" amplicons are then indexed by regular PCR using a dual-indexing system with the following parameters: (1) $72^{\circ} \mathrm{C}$ for $3 \mathrm{~min},(2) 95^{\circ} \mathrm{C}$ for $30 \mathrm{sec}$, (3) $\left[95^{\circ} \mathrm{C}\right.$ for $10 \mathrm{sec}-55^{\circ} \mathrm{C}$ for $30 \mathrm{sec}-72^{\circ} \mathrm{C}$ for 30 
sec] $\times 12$ cycles, (4) $72^{\circ} \mathrm{C}$ for $5 \mathrm{~min}$, hold at $10^{\circ} \mathrm{C}$. Finally, indexed libraries were purified and quantified using a Bio-Analyser (Agilent). All samples were pooled based on their molarity at a $2 \mathrm{nM}$ concentration. Then, pooled libraries were mixed with $10 \%$ PhiX (to increase diversity of base calling during sequencing), denatured in $0.1 \mathrm{~N} \mathrm{NaOH}$, and diluted in $\mathrm{HT} 1$ buffer to a final $12 \mathrm{pM}$ concentration, which allows for an optimal cluster density of around $700-800 \mathrm{~K} / \mathrm{mm} 2$ on the flow cell. Libraries were sequenced on a Illumina MiSeq sequencer using the v3,600-cycle kit to perform a 300bp paired-end run, following the manufacturer's recommendations.

\section{Hydroxymethylcytosine Analysis (oxBS)}

We performed an analysis of methylated $(\mathrm{mC})$ and hydroxymethylated $(\mathrm{hmC})$ cytosines using the CEGX True Methyl kit (Cambridge Epigenetix), as recently described by Feng et al (6). Briefly, we prepared 47 DNA samples of 1.5 ug each by pooling DNA from 2 subjects $(0.75 \mathrm{ug} / \mathrm{subject})$ of the same $\mathrm{C}$, SA or SNA group. Following the manufacturer's recommendations, DNA from each pool was then split in 2 equal reactions, one of which underwent chemical oxidation followed by bisulfite conversion (oxBS-DNA), while the other underwent mock oxidation (oxidant replaced by water) followed by bisulfite conversion (BS-DNA). All bisulfite reactions were cleaned-up using a bead-based purification (1x AMPure Beads, Agencourt) and eluted in a final 20ul water volume.

For library preparation, we used a PCR-based approach recently implemented in our group (7). A first round of PCR amplification was performed on both oxBS-DNA and BS-DNA using the Kapa HIFI Uracil+ mastermix. Primers were designed using the MethyIPrimer Express software v1.0 (ThermoFischer Scientific). Primer sequences can be found in Supplementary Table 4. The PCR reaction parameters were: (1) $95^{\circ} \mathrm{C}$ for 3 min, (2) $\left[98^{\circ} \mathrm{C}\right.$ for $20 \mathrm{sec}-60^{\circ} \mathrm{C}$ for $15 \mathrm{sec}-72^{\circ} \mathrm{C}$ for $\left.15 \mathrm{sec}\right]$ x 40 cycles, (3) $72^{\circ} \mathrm{C}$ for 1 
min, hold at $4^{\circ} \mathrm{C}$. Amplicons were then purified twice using AMPURE Beads at a $1 \mathrm{x}$ concentration. A second round of PCR amplification (10 cycles) using the same conditions described above was then performed on the purified samples, this time using primers containing universal sequences: for each forward and reverse primer used to amplify BS-DNA during round1 PCR, an additional round2 primer was synthesized containing universalF and universalR sequences at the $5^{\prime}$ ends of the forward and reverse primers, respectively (see Supplementary Table 4). The PCR reaction was again purified twice with AMPURE Beads at a 1x concentration. Finally, a third round of PCR amplification (10 cycles) was performed to add Illumina adapters (P5 and P7, for attachment to the MiSeq flowcell) as well as 10 nucleotide-long, non-Illumina indices (corresponding to the 384 FLD single barcoding system initially developed by Fluidigm, California, USA). Round3 forward primers contained the universalF and P5 sequences, while round3 reverse primers contained the universalR, index and P7 sequences (singleindexing system, see Supplementary Table4). Two final purifications of 1x AMPURE Beads were performed. Libraires were quantified using the TapeStation Instrument and DNA 1000 reagents (Agilent). All libraries were pooled based on their molarity, mixed with $10 \%$ PhiX, denatured in $\mathrm{NaOH}$ and diluted to a final $12 \mathrm{pM}$ concentration in $\mathrm{HT} 1$ buffer.

For sequencing, we used a customized MiSeq approach specifically designed for the sequencing of libraries prepared as described above (7). In this approach, customized sequencing primers were used to maximise the reading of DNA inserts located directly at the 3' end of universal and universalR primers sequences. Accordingly, three customized sequencing primers, universalF-Compl (for Read1 sequencing, complementary to universalF sequence), universalR-ReverseCompl (for Index Reading, reverse complementary to universalR sequence), and universalR-Compl (for Read2 sequencing, complementary to universalR sequence) in locked nucleic acid 
form (LNA, EXIQON, see Supplementary Table 5) were loaded onto the reagent cartridge to replace Illumina's Read1, Index, and Read2 sequencing primers, respectively. Finally, libraries were sequenced on an Illumina MiSeq sequencer using the v3,600-cycle kit to perform a 300bp paired-end run, following the manufacturer's recommendations.

\section{Bioinformatic analysis}

Illumina adaptors (for both NEXTERA XT and oxBS experiments) and universal primers (oxBS only) were trimmed from the reads when encountered (using Trimmomatic 0.35 with the following parameters: ILLUMINACLIP:Fluidigm_primers.fa:3:30:9 HEADCROP:3 LEADING:20 TRAILING:20 SLIDINGWINDOW:4:20 MINLEN:50, Fluidigm_primers.fa containing the primers). Sequencing reads were also trimmed when Phred quality scores dropped below a threshold of 20. Bismark v0.14.4 was used to align reads to the targeted genomic regions using hg19 human genome as a reference. Bismark was ran with Bowtie 2 (version 2.1.0). The extraction of the number of unconverted and converted cytosine for each CG was done with the script bismark_methylation_extractor provided with Bismark with the following parameters: -p --no_overlap --cytosine_report -counts -s -bedGraph. All cytosines in both NEXTERA and oxBS experiments had coverages above 5 (Fig.S3, 8D), and therefore all data were included into statistical analyses. In NEXTERA XT experiments, the DNA methylation percentage was calculated for each cytosine as the unconverted (cytosines, C) read counts divided by total read counts ( $C$ and Thymines, $T$ ). In oxBS experiments, the $5 \mathrm{mC}$ percentage of each cytosine was calculated from the oxBS reaction as the unconverted read counts divided by total read counts. The $5 \mathrm{hmC}$ percentage of each cytosine was derived by subtracting the unconverted read counts in oxBS reaction to the unconverted read counts in BS reaction. 


\section{Luciferase Assays}

A 850-bp sequence of the Kappa opioid receptor Intron2 (Kappa-i2) containing the glucocorticoid response element (GRE) documented by ENCODE data (Fig.S8) was amplified from genomic DNA by regular PCR, with primers including (i) Scal and Spel restriction sites for the Basic construct, or (ii) BamHI and Spel for the Promoter construct (see Supplementary Table 6 for primers sequences). The amplified fragments were digested with the corresponding restriction enzymes, purified and subsequently ligated into either CpGfree-Basic or CpGfree-Promoter (InvivoGen) luciferase reporter vectors, respectively. In vitro DNA methylation of the reporter constructs was carried out using the M.Sssl CpG Methyltransferase (NEB) and according to the manufacturer's instructions. Successful methylation was confirmed by restriction digestion with Hpall (NEB), whereby linearization of the plasmids is blocked by $\mathrm{CpG}$ methylation. Methylated and unmethylated constructs were subsequently transfected. All constructs were verified by Sanger sequencing (see Supplementary Table 6). These vectors were then transfected in either (i) the SK-N-AS human neuroblastoma cell line, purchased from ATCC and maintained in Dulbecco's modified Eagle's medium (DMEM) containing 10\% fetal bovine serum, 0.1mM Non-Essential Amino Acid (NEAA), $100 \mathrm{U} / \mathrm{ml}$ Penicillin and $100 \mathrm{ug} / \mathrm{ml}$ Streptomycin in incubator at $37^{\circ} \mathrm{C}$ with $5 \% \mathrm{CO} 2$, or in (ii) the HeLa cell line purchased from ATCC and maintained in Eagle's Minimum Essential Medium (EMEM, ATCC) containing $10 \%$ fetal bovine serum, $100 \mathrm{U} / \mathrm{ml}$ Penicillin and $100 \mathrm{ug} / \mathrm{ml}$ Streptomycin in incubator at $37^{\circ} \mathrm{C}$ with $5 \% \mathrm{CO}$. Cells were seeded into 48 -well plates, transiently co-transfected with $197.5 \mathrm{ng}$ of Lucia luciferase reporter vector containing the KOR-i2 sequence and 2.5ng of Firefly luciferase vector. Vectors were transfected using FuGene HD Reagent (Promega). Luciferase assay was performed 24 hours after transfection. The supernatant from each well was collected, cells were washed with PBS 
twice, lysed by rocking the plate for $15 \mathrm{~min}$ at room temperature, and luciferase activities were measured using a Dual-Luciferase Reporter Assay System in quintuplicates. The relative luciferase activity was calculated as the ratio Lucia-luciferase activity/Fireflyluciferase activity for normalization by transfection efficacy. Dexamethasone stimulation experiments were conducted as described by Klengel et al (8). HeLa cells were transfected with the aforementioned constructs and stimulated with $50 \mathrm{nM}$ dexamethasone for $24 \mathrm{~h}$. 


\section{B. Legends of supplementary Figures}

Supplementary Figure 1. Quantification of gene expression using GPCR. (A) Efficiencies of PCR amplification observed for each gene of interest were between $100 \pm$ $15 \%$ for all genes. (B-H) Representative examples of calibration curves obtained following serial dilutions and PCR amplification of pooled cDNAs (see Material \& Methods).

Supplementary Figure 2. Quantification, using Nanostring, of 3 additional housekeeping control genes: GUSB, RPL13, and Tubulin. (A) Expression of $\beta$-actin, which was used in RT-PCR screening of opioid receptors and peptides (see main text, Fig.1) was normalized relative to the expression of GUSB, RPL13, and Tubulin. Results indicate that expression of $\beta$-actin was not different among $C$, SA and SNA groups when quantified relative to these 3 control genes $(p=0.53)$. (B) Similarly, expression of the $2^{\text {nd }}$ housekeeping gene used during RT-PCR screening of the opioid system, GAPDH, was not differentially expressed across groups $(p=0.22)$. Therefore, the downregulation of Kappa, which associated in the anterior insular cortex with a history of child abuse (Fig.1), is not driven by a potential change in the expression of the 2 reference genes used as controls.

Supplementary Figure 3. Age-related changes in opioid receptors and peptides expression in the human brain. In the anterior cingulate cortex (ACC, panel A), expression of Enk significantly correlated with age $(p<0.0068)$. In the medio-dorsal thalamus (MDT, panel B) and anterior insula (Al, panel C), the mu $(\mathrm{Mu})$ and kappa (Kappa) opioid receptors exhibited opposite patterns of regulation during aging: expression of both receptors increased in the MDT $\left(M u r^{2}=0.11, p=0.014\right.$; Kappa $\left.r^{2}=0.093, p=0.026\right)$, while their expression decreased in the Al $\left(\mathrm{Mu} r^{2}=0.11, p=0.0070\right.$; 
Kappa $r^{2}=0.098, p=0.0023$ ), suggesting that there might be some relationship between the expression of these 2 receptors in these 2 brain regions.

Supplementary Figure 4. Relative expression of kappa opioid receptor (Kappa) variants 1 (NM_000912.4) and 2 (NM_001282904.1) across the anterior insula, the anterior cingulate cortex (ACC), and the mediodorsal thalamus (MD Thalamus). (A) Expression of Kappa variants was assessed by RT-qPCR using primer pairs specifically amplifying each variant. (B) We used the $\Delta \mathrm{Ct}$ method to compare the expression of each variant with the expression of the variants $1 \& 2$ combined. The protein that is potentially encoded by Kappa variant 2 is predicted to lack the first two transmembrane domains that are necessary for trafficking of the receptor at the plasma membrane. The potential function of this truncated protein, if any, remains elusive. Nevertheless, we note that variant 2 expression was readily detected across all 3 brain regions examined, although at approximatively a 10-time lower level than variant 1 .

Supplementary Figure 5. Coverage in NEXTERA XT experiments. DNA methylation was measured in 7 genomic regions of the kappa opioid receptor gene. High coverage was achieved throughout the 7 regions, as shown here with the average coverage in the entire cohort of samples. All cytosines met a $5 X$-treshold criteria in every sample, and were therefore included into differential methylation analyses. Of note, a group of $4 \mathrm{CpG}$ sites located within exon1 showed a comparatively low coverage averaging between $11.1 \pm 0.5$ and $43.7 \pm 1.8$, which likely reflects the sequence-dependent activity of the transposome enzymes used for "tagmentation" during NEXTERA XT library preparation.

Supplementary Figure 6. DNA methylation in psychiatrically healthy subjects (controls, C), suicide completers with a history of child abuse (CA), and suicide completers with no 
history of child abuse (SNA) in the kappa opioid receptor exon1. In this genomic region, we found no evidence for differential DNA methylation among C, CA and SNA subjects $[F(2,91)=0.26 ; p=0.77]$, while there was, as expected, a strong difference in DNA methylation among CG sites $[F(51,4641)=101.8 ; p<0.0001]$, without any interaction between the 2 factors $[F(102,4641)=0.74 ; p=0.98]$.

Supplementary Figure 7. DNA methylation in psychiatrically healthy subjects (controls, C), suicide completers with a history of child abuse (CA), and suicide completers with no history of child abuse (SNA) in the kappa opioid receptor exon2. In this genomic region, there was no significant differences across C, CA and SNA groups $[F(2,91)=0.67$; $p=0.51]$, while again CGs significantly differed $[F(45,4095)=120.5 ; p<0.0001]$, in the absence of an interaction $[F(90,4095)=0.55 ; p>0.99]$.

Supplementary Figure 8. DNA methylation in control (C), suicide completers with a history of child abuse (CA), and suicide completers with no history of child abuse (SNA) in the kappa opioid receptor exon 3 (A-B) and exon 4 (C-D). In exon 3, methylation levels significantly differed among $C G$ sites $[F(9,819)=38.14 ; p<0.0001]$, while there was no difference among $C, C A$ and SNA subjects $[F(2,91)=0.65 ; p=0.52]$ and no interaction $[F(18,819)=1.20 ; p=0.26]$. In exon 4 , we also found differences among $C G$ sites $[F(18,1638)=105.6 ; p<0.0001]$, but no group difference $[F(2,91)=0.95 ; p=0.39]$ and no interaction $[F(36,1638)=1.01 ; p=0.45]$.

Supplementary Figure 9. (A) Schematic representation of the kappa opioid receptor (Kappa) intron2 genomic region (User Track), which contains 11 CG sites (Short Match = CG) and where differences in DNA methylation were identified as a function of child abuse (see main text). Data from the ENCODE genome-wide database are depicted in 
the bottom track, and provide evidence that 4 transcription factors may bind to Kappa intron2: the glucocorticoid receptor, GR (gene name: NR3C1); GABPA; HNF4A; HNF4G). Because a large body of literature implicates a dysregulation of the HPA axis in long-term consequences associated with child abuse (9), we decided to focus on the GR binding site. (B) Higher-resolution representation of the GR binding site documented by ENCODE in the Kappa gene (coordinates of the corresponding ChIP-Seq peak: chr8: $54,151,276-54,151,525)$. This site overlapps with CG1, and is located within 356 base pairs of the other CGs (CG2 to CG11) for which we observed significant differences in DNA methylation as a function of child abuse (see main text, and Fig.3E). (C) Representation of the putative GR binding motif in Kappa intron2, as of ENCODE data (coordinates: chr8: $54,151,399-54,151,413$; also shown in green in panel $\mathrm{B}$, within the ENCODE ChIP-Seq peak).

Supplementary Figure 10. Regulation of the kappa opioid receptor by glucocorticoid signaling. (A) We focused on the potential regulation of Kappa by the glucocorticoid receptor (GR), and first tested whether the GR ligand dexamethasone (DXM) would potentiate GR binding at Kappa intron2 using a Luciferase reporter assay. The SK-N-AS and HeLa cells were exposed to a wide range of DXM concentration during 24 hours, as described previously (8), and we then measured Luciferase activity. A two-way ANOVA indicated that DXM significantly enhanced reporter activity $[F(3,24)=35.91 ; p<0.0001]$, while there was also a significant difference between the 2 cell lines $[F(1,8)=304$; $p<0.0001]$ and an interaction $[F(3,24)=1.01 ; p=0.45]$. Post-hoc comparisons showed that DXM induced a strong increase of Luciferase activity in the HeLa cell line at every DXM dose tested $(p<0.0001)$, while the drug had no effect in SK-N-AS cells $(p>0.15)$. (B) As an additional control experiment, we also explored the potential effect of GR stimulation at baseline, i.e. in the absence of the Kappa-i2 region, on the two Basic and EF1 $\alpha$ - 
Promoter constructs transfected in HeLa cells. We found significant differences in Luciferase activity between constructs $[F(1,16)=520 ; p<0.0001]$, with a significant effect of DXM $[F(1,16)=261 ; p<0.0001]$ and an interaction between factors $[F(1,16)=254$; $\mathrm{p}<0.0001]$. Post-hoc comparisons showed that reporter activity of the Promoter construct $(p<0.0001)$, but not of the Basic construct $(p>0.99)$, is significantly enhanced by DXM stimulation. We note that these results are consistent with the notion that ENCODE data document a binding site for GR within the EF1 $\alpha$ promoter (C). Therefore, to avoid the confounding effect of DXM at the EF1 $\alpha$ promoter, we used the Basic construct to explore how DNA methylation of Kappa intron2 may regulate GR binding (see main text, Fig.4)

Supplementary Figure 11. Quantification of GR expression in the anterior insula using RT-PCR. Because previous studies found that GR expression was decreased in the hippocampus (10), but not in the anterior cingulate cortex (11), of subjects with a history of child abuse, we postulated that dysregulation of GR expression might occur in the anterior insula. However, we found no evidence of GR dysregulation by child abuse in this brain region $[F(1,93)=1.01 ; p=0.32]$, reinforcing the hypothesis that decreased Kappa expression in anterior insula of abused subjects (CA group) may not stem from impaired GR signalling.

Supplementary Figure 12. Quality controls in oxBS experiments. (A) Spike-in digestion control sequences contain a $5 \mathrm{hmC}$ mark at the TCGA Taq $\alpha 1$ restriction enzyme digestion site. An efficient oxidation (ox) reaction will convert this $5 \mathrm{hmC}$ to thymidine after bisulfite conversion, which will prevent the enzyme from cutting. In the bisulfitealone (bs) reaction, the $5 \mathrm{hmC}$ will remain a cytosine after the bisulfite reaction and will be cut by the enzyme. Digestion control reactions were run with (+) and without (-) the 
restriction enzyme and an addition cutting control was included, also with (+) and without (-) the restriction enzyme. (B-C) During PCR amplification of targeted genomic regions, primers were also designed to interrogate the spiked-in sequencing controls provided in the True Methyl kit (CEGX), which contain a variety of $5 \mathrm{hmC}, 5 \mathrm{mC}, 5 \mathrm{fC}$, and $\mathrm{C}$ bases. Conversion rates of cytosine to thymidine in for the oxBS (B) and BS (C) reactions were as expected, with $5 \mathrm{hmC}$ being converted to thymidine after oxidation and bisulfite conversion (B), but not after bisulfite conversion only (C). (D) Coverage achieved in oxBS experiments. All three cytosines met a 5X-treshold criteria in every sample, and were therefore included into differential methylation analyses.

\section{References}

1. Mai JK, Paxinos G, Voss T (2007): Atlas of the Human Brain, Third Edition. Elsevier Science.

2. M'Boutchou M-N, van Kempen L (2016): Analysis of the Tumor Microenvironment Transcriptome Via NanoString mRNA and miRNA Expression Profiling. The Tumor Microenvironment: Methods and Protocols (Methods in Molecular Biology). Humana Press; 1 st ed.

3. Lutz PE, Tanti A, Gasecka A, Barnett-Burns S, Kim JJ, Zhou Y, et al. (In press): Convergent epigenetic, transcriptional and morphological evidence associate a history of child abuse with impaired myelination in the anterior cingulate cortex. Am J Psychiatry.

4. Geiss GK, Bumgarner RE, Birditt B, Dahl T, Dowidar N, Dunaway DL, et al. (2008): Direct multiplexed measurement of gene expression with color-coded probe pairs. Nat Biotechnol. 26:317-325.

5. Masser DR, Berg AS, Freeman WM (2013): Focused, high accuracy 5methylcytosine quantitation with base resolution by benchtop next-generation sequencing. Epigenetics Chromatin. 6:33.

6. Feng J, Shao N, Szulwach KE, Vialou V, Huynh J, Zhong C, et al. (2015): Role of Tet1 and 5-hydroxymethylcytosine in cocaine action. Nat Neurosci.

7. Chen GG, Gross JA, Lutz PE, Vaillancourt K, Maussion G, Bramoulle A, et al. (Submitted): A medium throughput bisulfite sequencing approach to analyze 5methylcytosine and 5-hydroxymethylcytosine

8. Klengel T, Mehta D, Anacker C, Rex-Haffner M, Pruessner JC, Pariante CM, et al. (2013): Allele-specific FKBP5 DNA demethylation mediates gene-childhood trauma interactions. Nat Neurosci. 16:33-41.

9. Turecki G, Meaney MJ (2014): Effects of the Social Environment and Stress on Glucocorticoid Receptor Gene Methylation: A Systematic Review. Biol Psychiatry.

10. McGowan PO, Sasaki A, D'Alessio AC, Dymov S, Labonte B, Szyf M, et al. (2009): Epigenetic regulation of the glucocorticoid receptor in human brain associates with childhood abuse. Nat Neurosci. 12:342-348.

11. Labonte B, Yerko V, Gross J, Mechawar N, Meaney MJ, Szyf M, et al. (2012): Differential glucocorticoid receptor exon $1(\mathrm{~B}), 1(\mathrm{C})$, and $1(\mathrm{H})$ expression and methylation in suicide completers with a history of childhood abuse. Biol Psychiatry. 72:41-48. 


\section{Supplementary Figures}

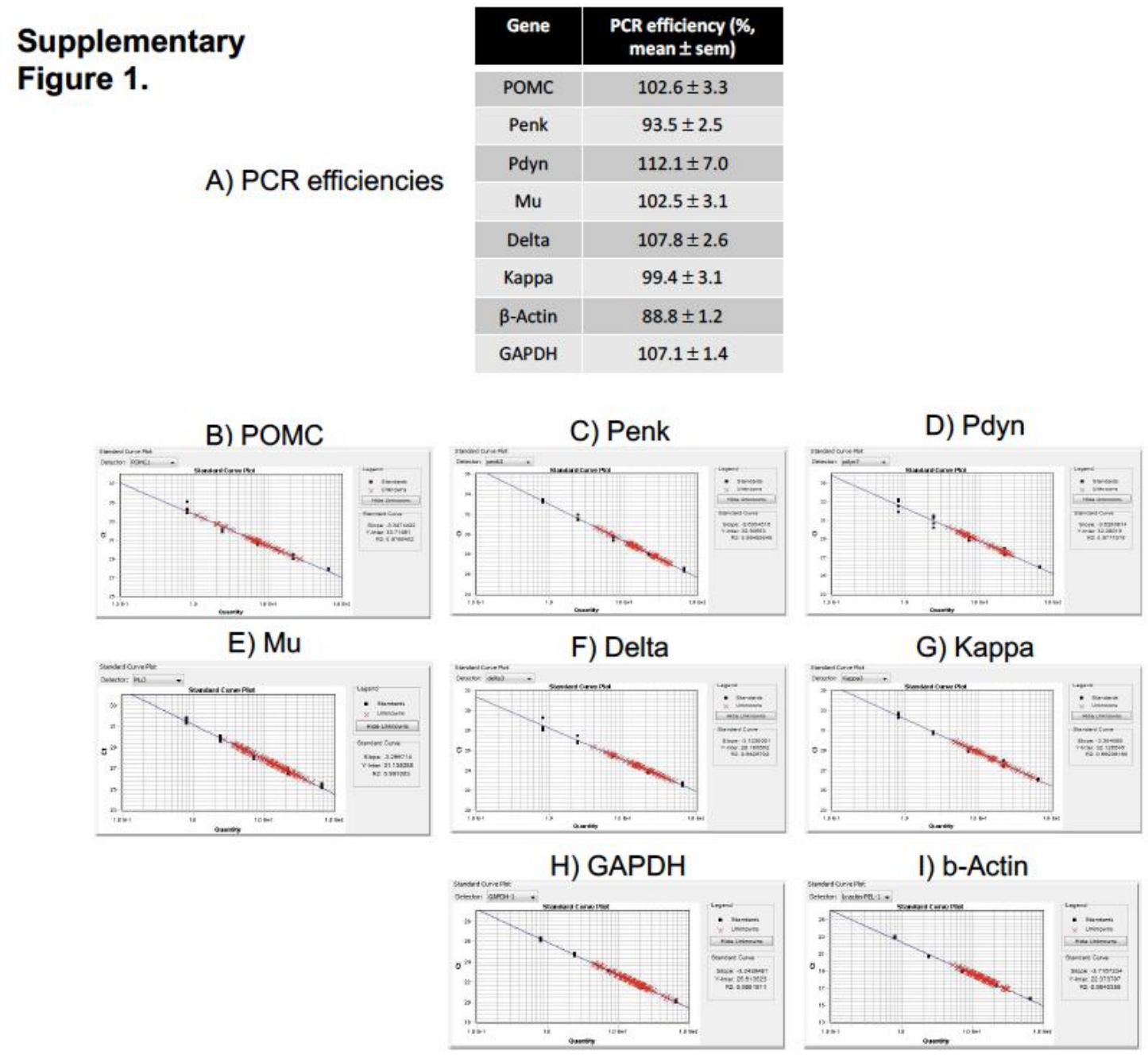


Supplementary Figure 2.

A)

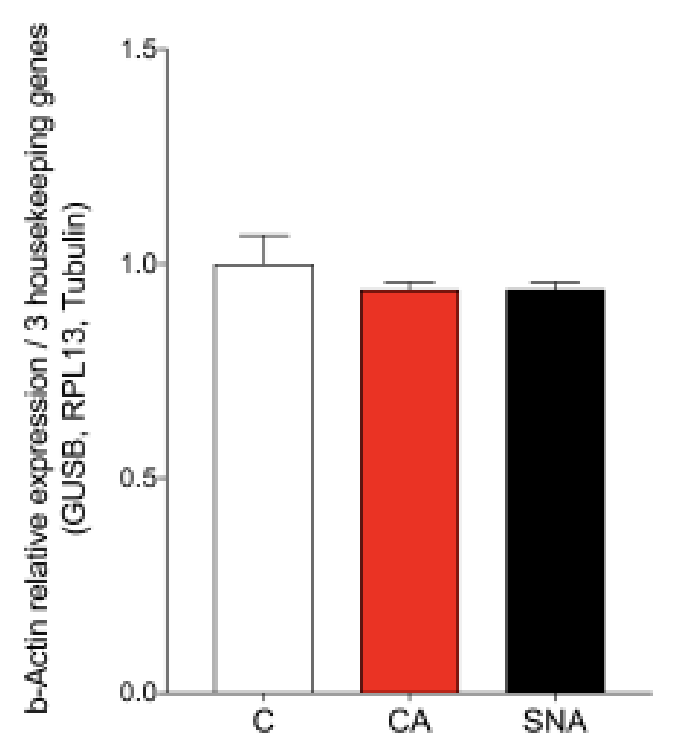

B)

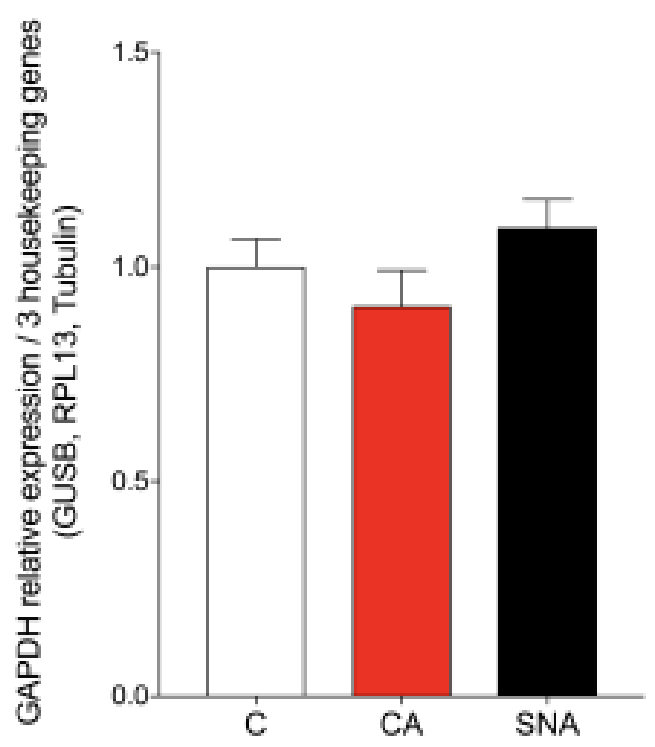




\section{Supplementary}

Figure 3.

A) Anterior

Cingulate cortex

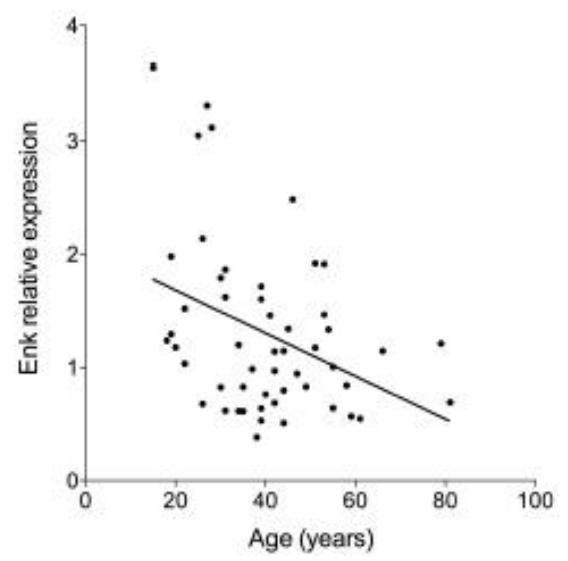

B) Medio-Dorsal

Thalamus
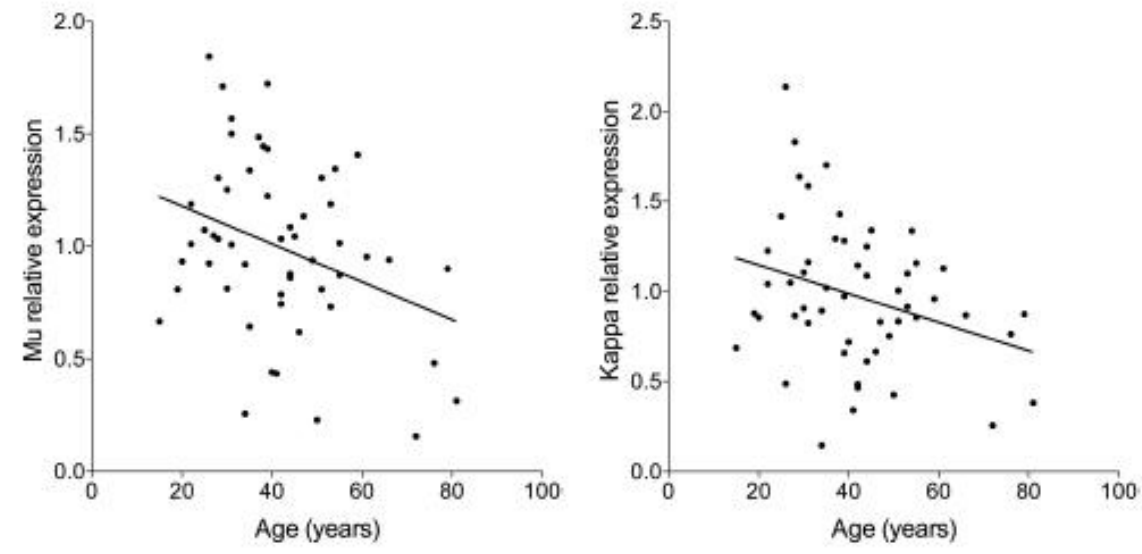

C) Anterior Insula
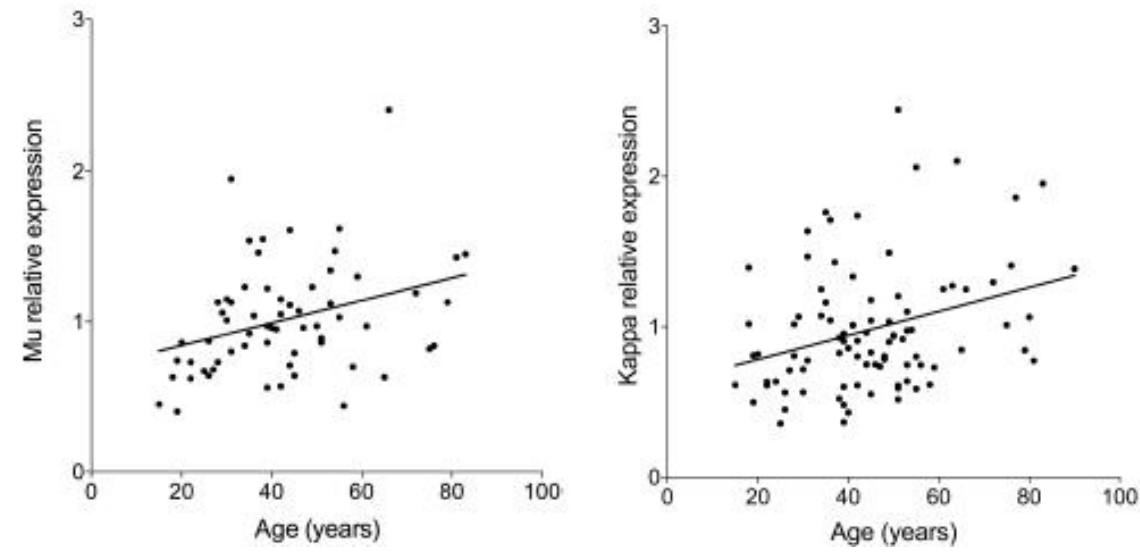


\section{Supplementary Figure 4.}

A)

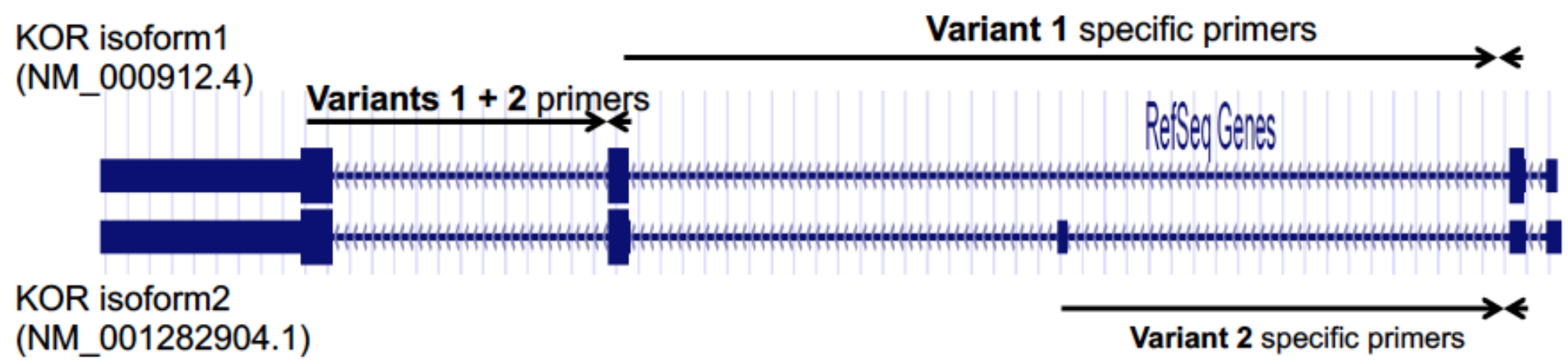

B)

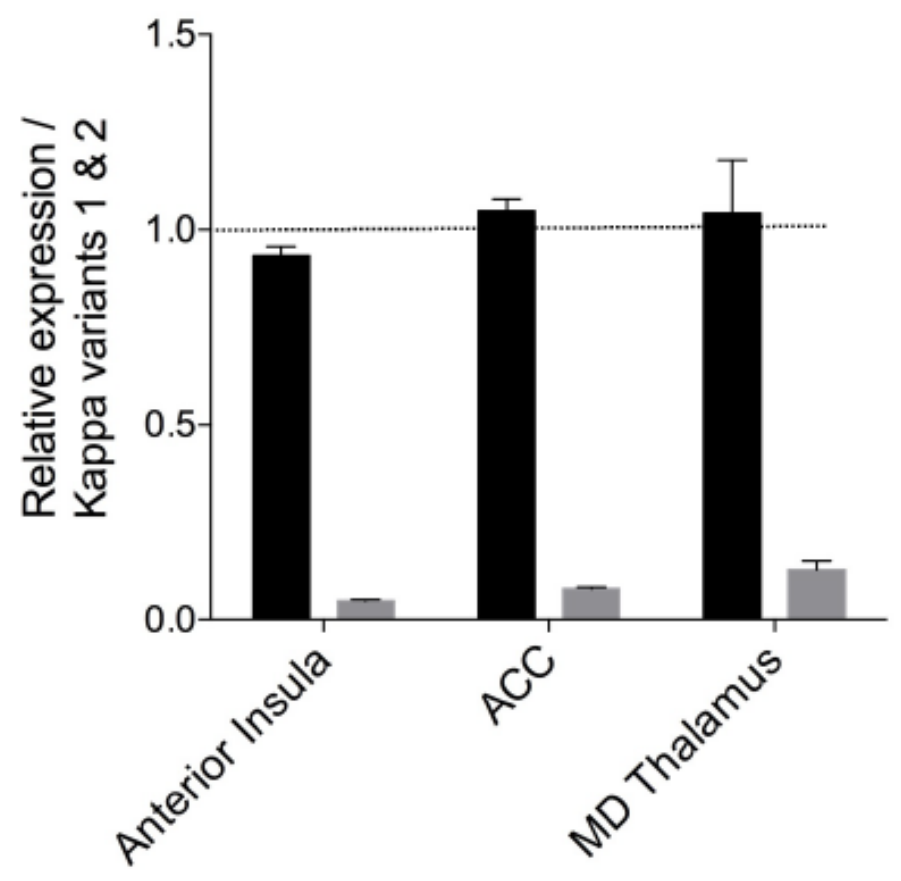

- Variant1

Variant2 


\section{Supplementary Figure 5.}
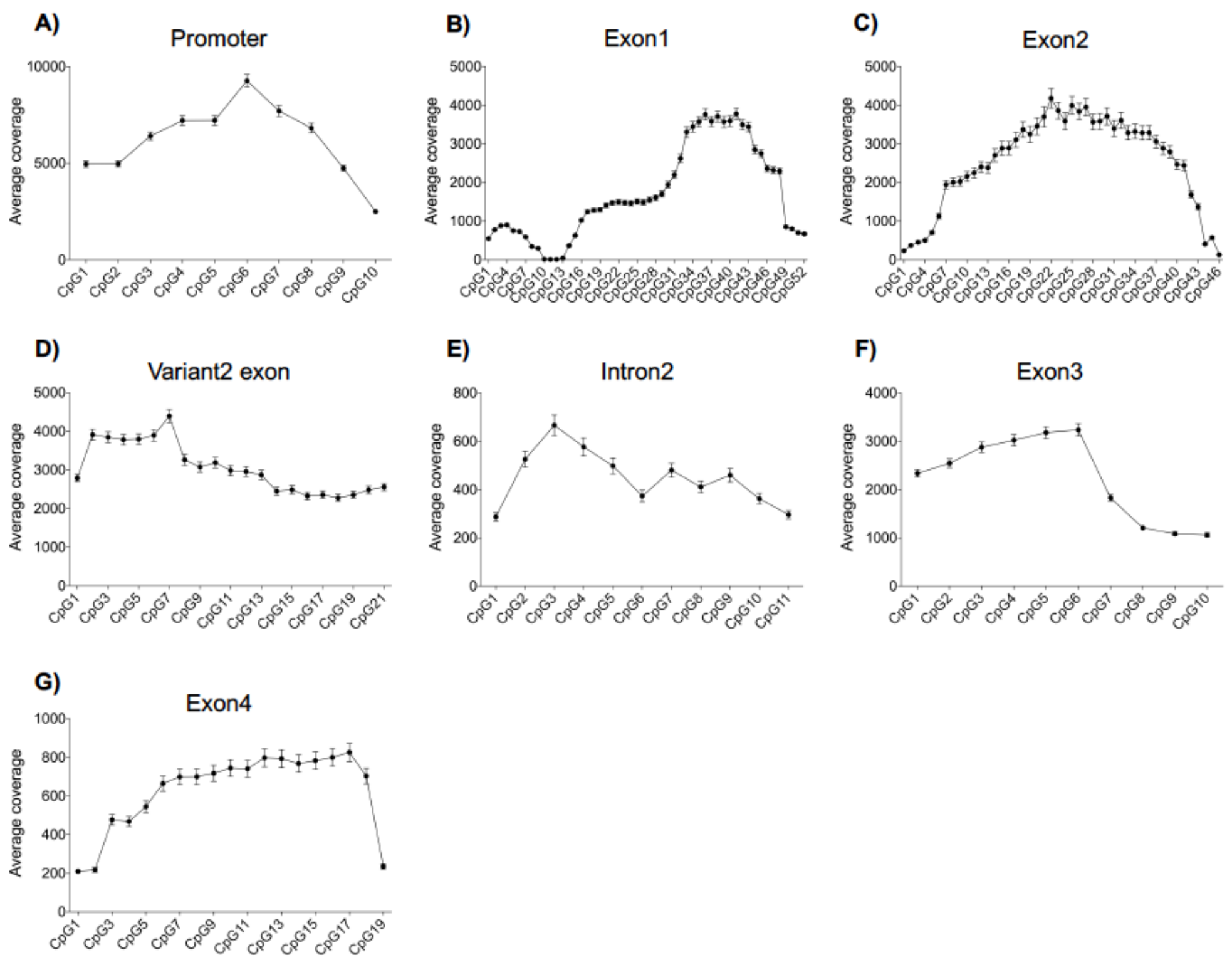


\section{Supplementary Figure 6.}

A)
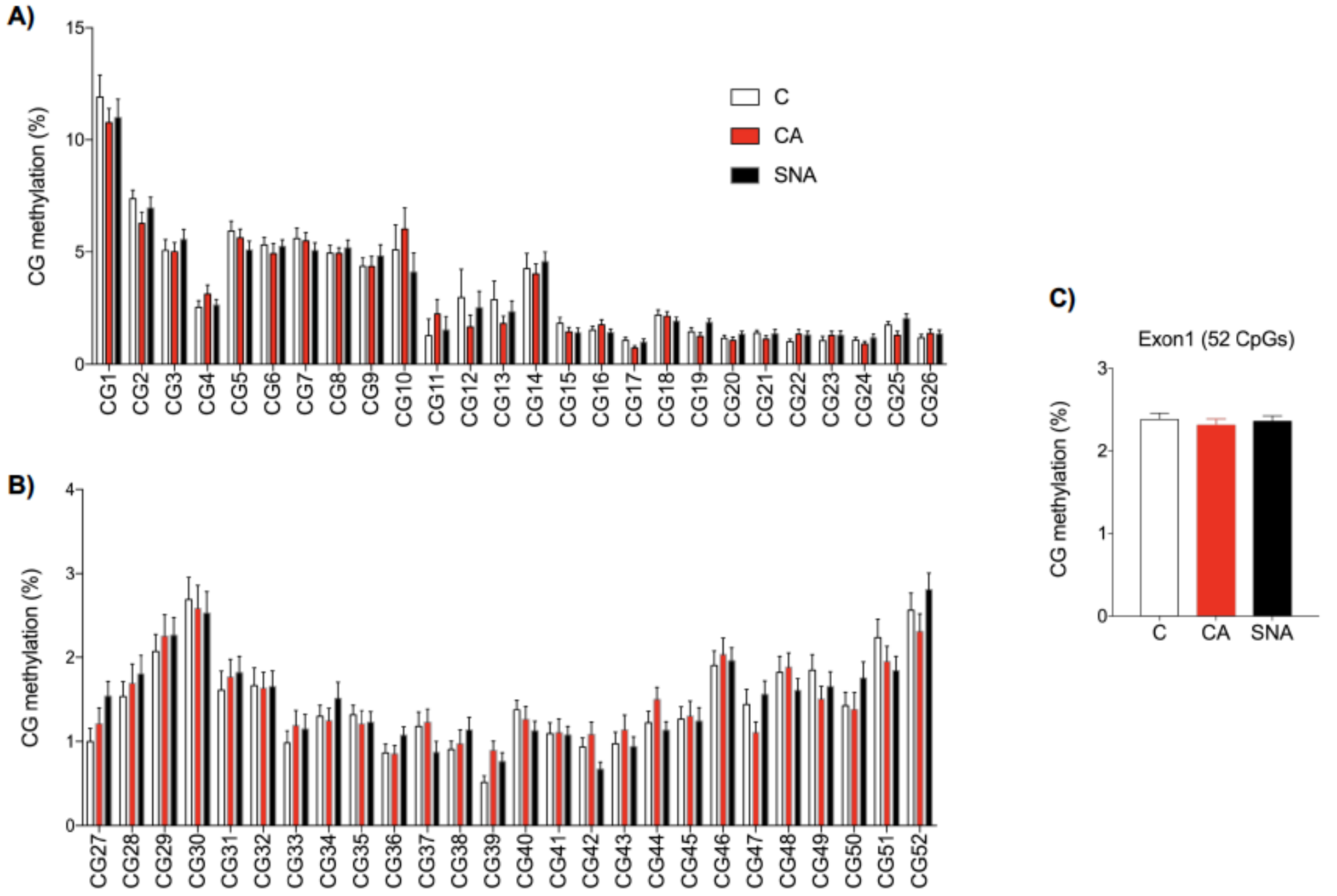


\section{Supplementary Figure 7.}
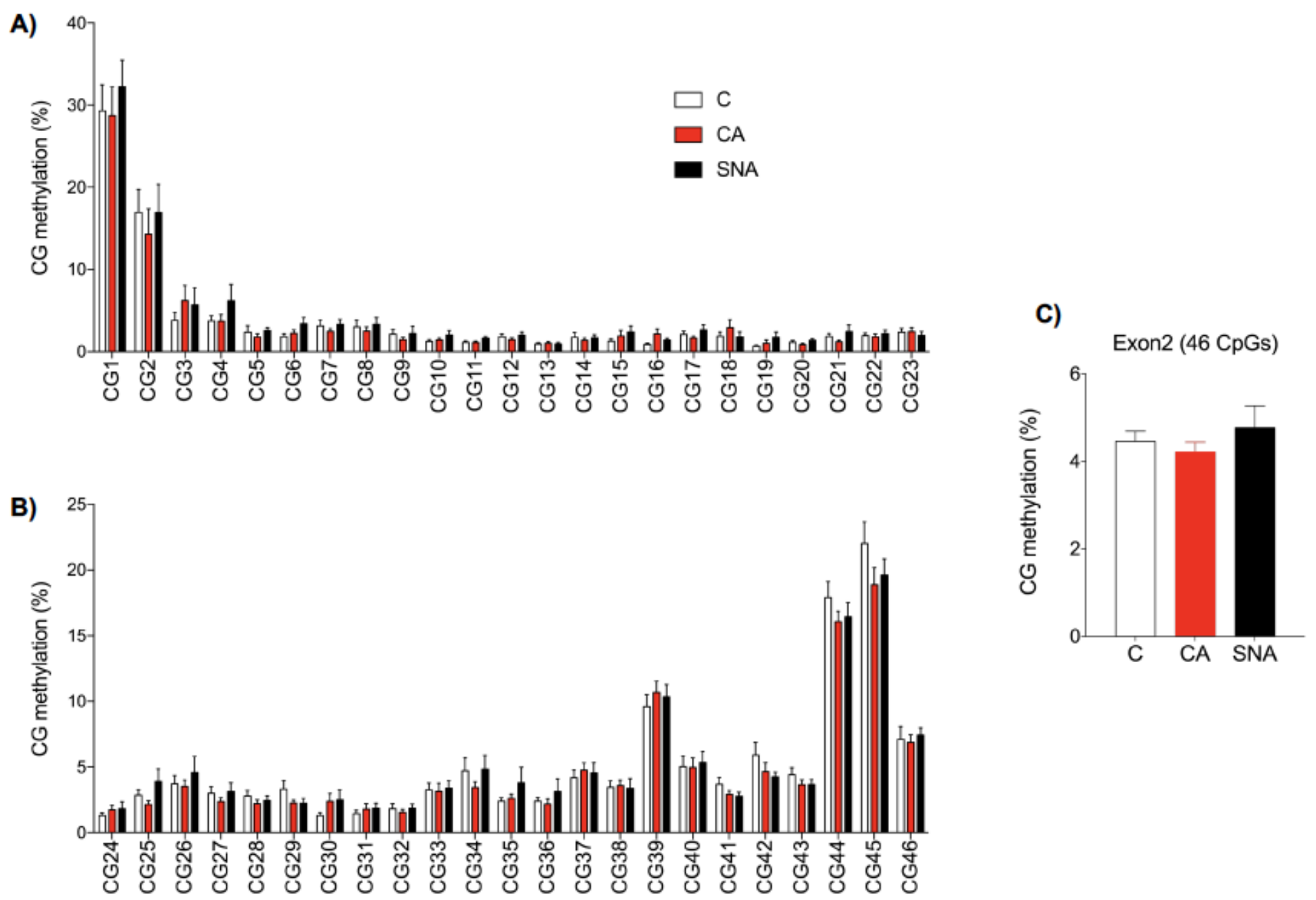
Supplementary Figure 8.

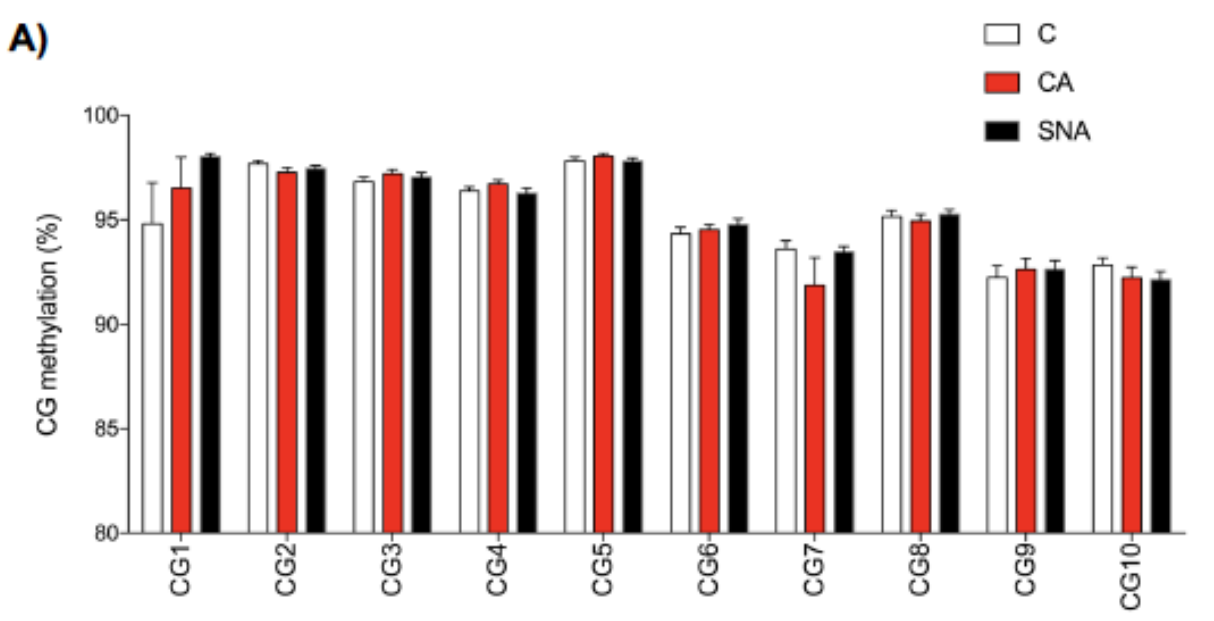

B) $\quad$ Exon3 (10 CpGs)

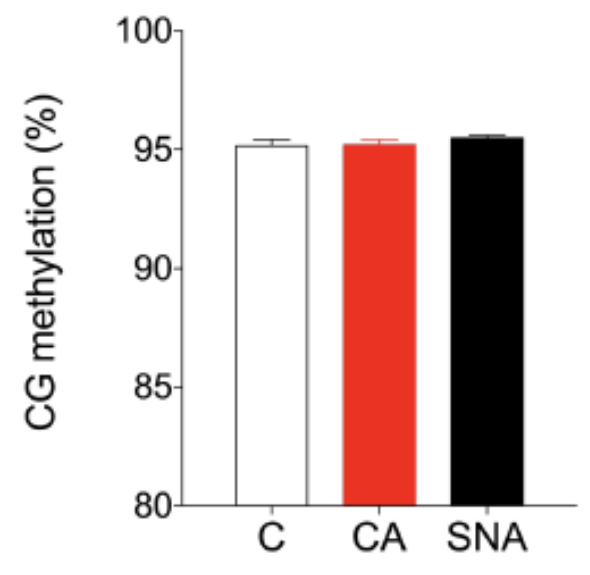

C)

D)

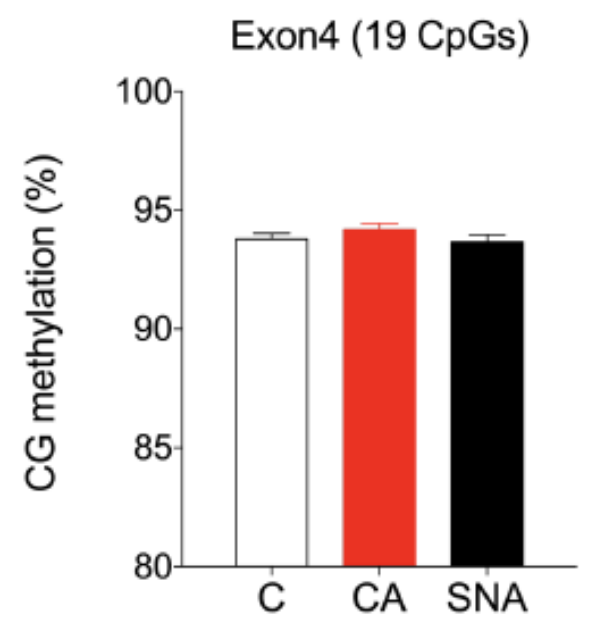




\title{
Supplementary Figure 9.
}

A)

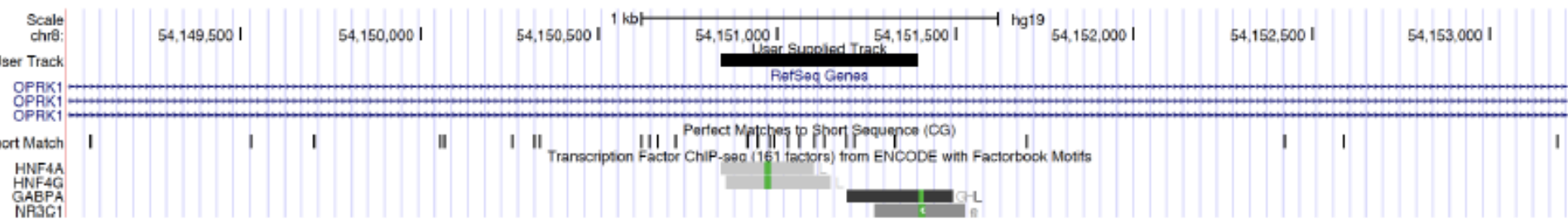

B)

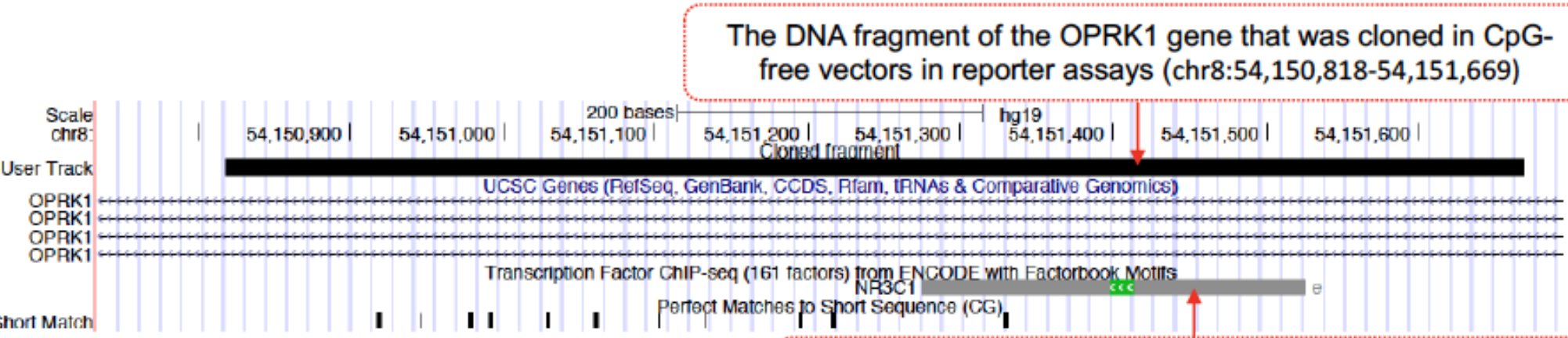

Short Match

I I I

The NR3C1 ChIP-Seq peak documented by ENCODE data (chr8:54,151,276-54,151,525)

C)

\author{
Motif Name: NR3C \\ Motif Score: 2.36 \\ Motif Position: chr8:54151399-54151413 \\ Motif Strand: -
}

Motif display help

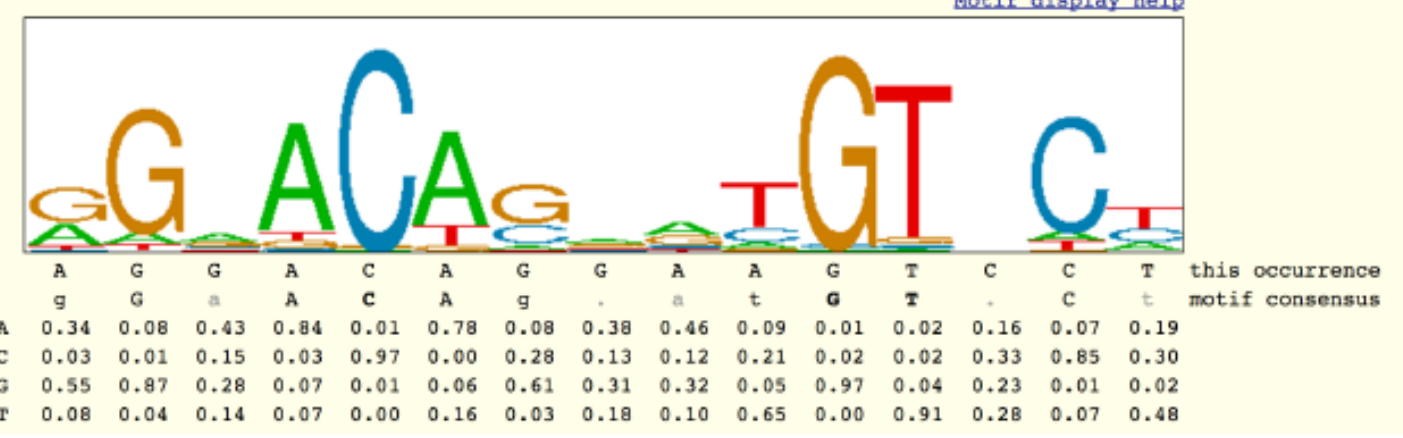




\section{Supplementary Figure 10.}

A)

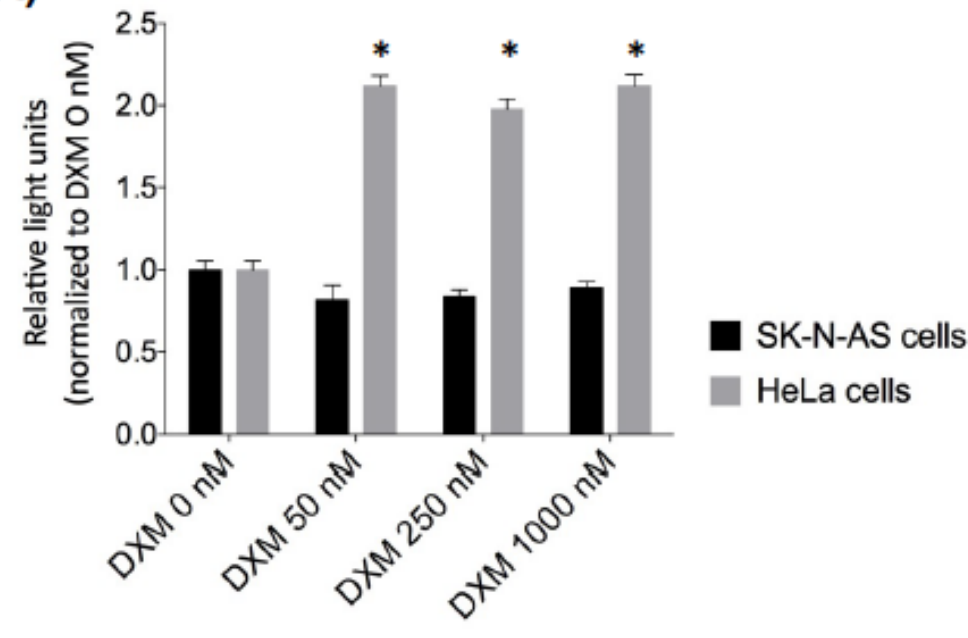

B)

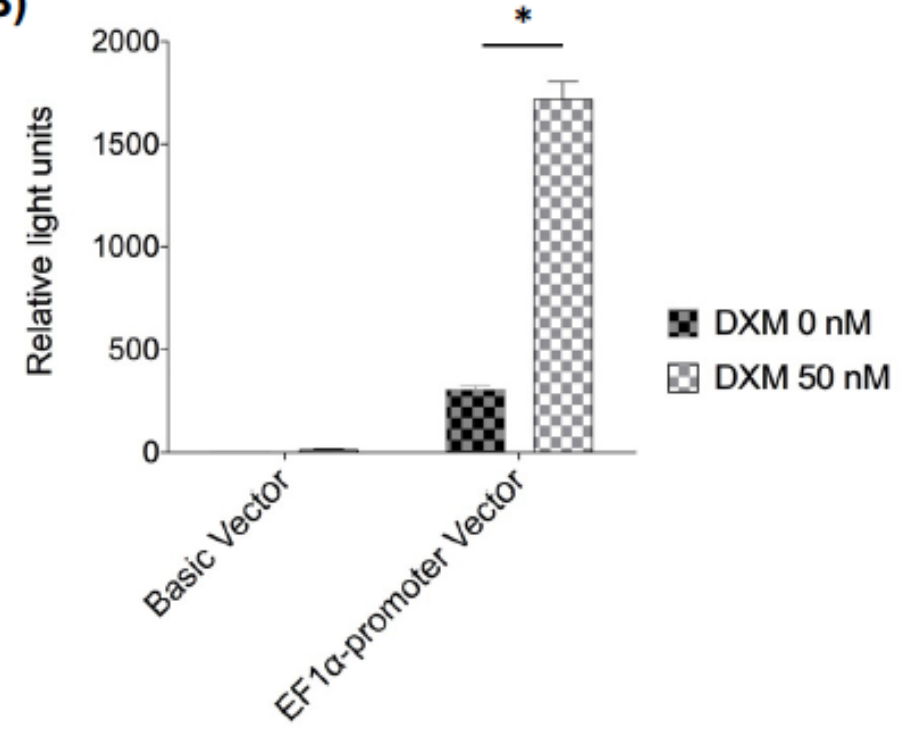

C)

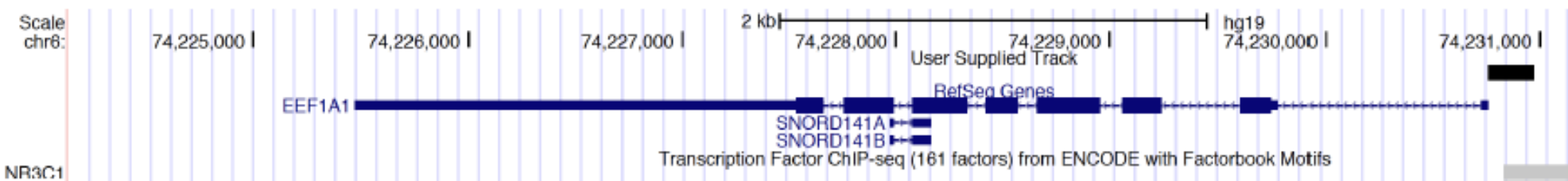


Supplementary Figure 11.

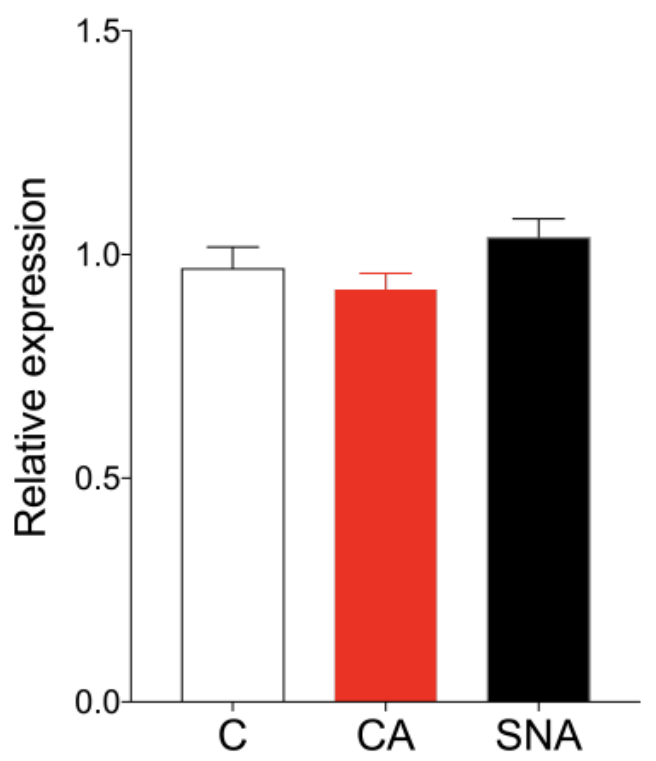


Supplementary Figure 12.

A)

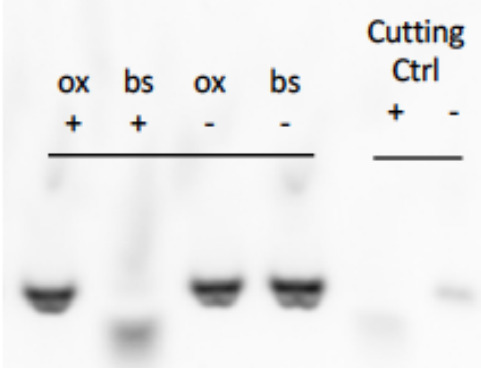

D)

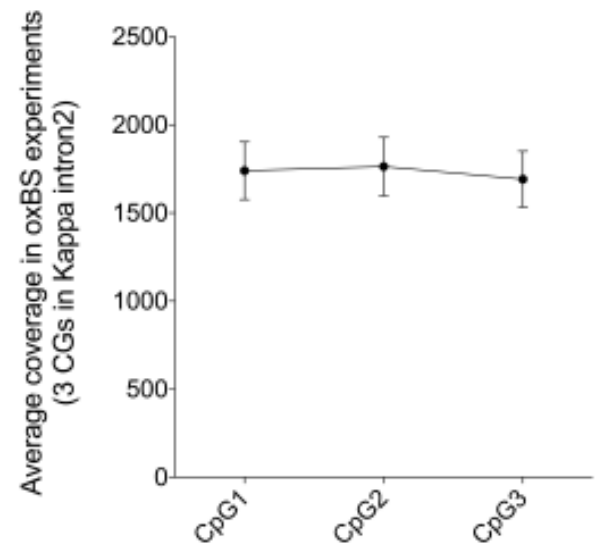

B)

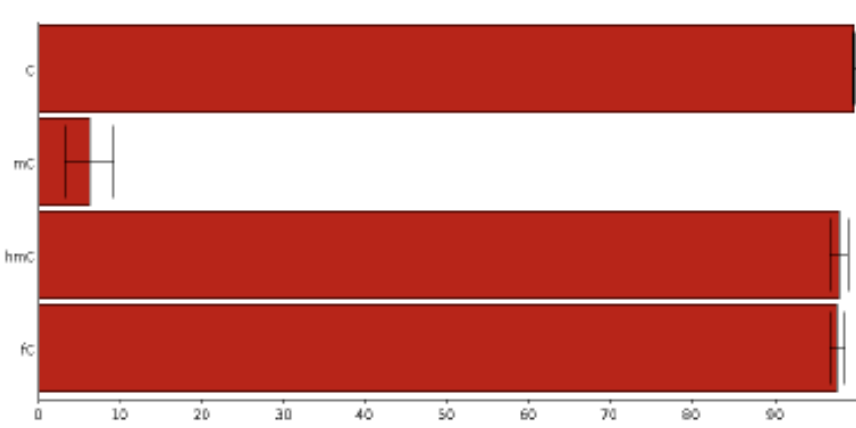

C)

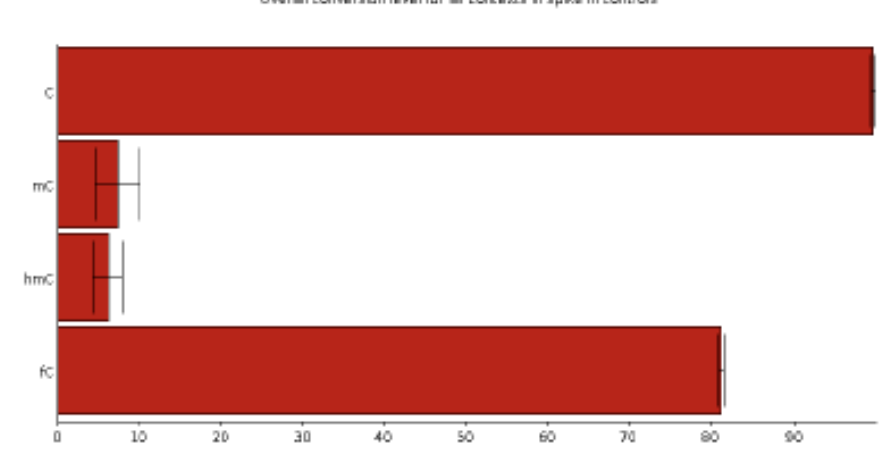




\section{Supplementary Tables}

Supplementary Table 1. Groups were composed of (i) psychiatrically healthy controls (C), (ii) suicide completers with a history of child abuse (CA), and (iii) suicide completers without any history of child abuse (SNA), and were matched for covariates, including age, $\mathrm{pH}$, postmortem interval (PMI), RNA integrity number (RIN), and gender. P-values correspond to one-way ANOVAs (age, pH, $\mathrm{PMI}$ and RIN) or Chi-square (gender).

\begin{tabular}{|c|c|c|c|c|}
\hline $\begin{array}{c}\text { Mediodorsal } \\
\text { thalamus }\end{array}$ & C & CA & Stats & \\
\hline $\mathrm{N}$ & 27 & 26 & - & \\
\hline Age (years) & $44.9+/-3.6$ & $39.6+/-2.1$ & $p=0.22$ & \\
\hline $\mathrm{pH}$ & $6.52+/-0.06$ & $6.63+/-0.06$ & $p=0.20$ & \\
\hline Postmortem interval & $24.7+/-3.2$ & $24.8+/-3.7$ & $p=0.99$ & \\
\hline $\begin{array}{l}\text { RNA integrity number } \\
\text { gender }(M / F)\end{array}$ & $\begin{array}{c}5.96+/-0.10 \\
23 / 4\end{array}$ & $\begin{array}{c}5.92+/-0.10 \\
20 / 6\end{array}$ & $\begin{array}{l}p=0.80 \\
p=0.44\end{array}$ & \\
\hline $\begin{array}{c}\text { Anterior cingulate } \\
\text { cortex }\end{array}$ & C & CA & Stats & \\
\hline $\mathrm{N}$ & 26 & 26 & - & \\
\hline Age (years) & $42.3+/-3.6$ & $39.2+/-2.1$ & $p=0.063$ & \\
\hline $\mathrm{pH}$ & $6.5+/-0.06$ & $6.6+/-0.06$ & $\mathrm{p}=0.41$ & \\
\hline Postmortem interval & $24.6+/-3.3$ & $25.4+/-3.6$ & $p=0.99$ & \\
\hline RNA integrity number & $6.29+/-0.17$ & $6.45+/-0.17$ & $p=0.12$ & \\
\hline gender (M/F) & 23 / 3 & $21 / 5$ & $p=0.73$ & \\
\hline $\begin{array}{l}\text { Anterior } \\
\text { insula }\end{array}$ & C & CA & SNA & Stats \\
\hline $\mathrm{N}$ & 34 & 30 & 30 & - \\
\hline Age (years) & $46.3+/-3.5$ & $43.4+/-2.5$ & $47.1+/-2.5$ & $p=0.70$ \\
\hline $\mathrm{pH}$ & $6.50+/-0.06$ & $6.57+/-0.06$ & $6.61+/-0.06$ & $p=0.43$ \\
\hline Postmortem interval & $23.5+/-3.0$ & $27.7+/-3.8$ & $25.9+/-3.8$ & $p=0.70$ \\
\hline $\begin{array}{l}\text { RNA integrity number } \\
\text { gender (M/F) }\end{array}$ & $\begin{array}{c}6.86+/-0.16 \\
29 / 5\end{array}$ & $\begin{array}{c}6.92+/-0.19 \\
23 / 7\end{array}$ & $\begin{array}{c}7.38+/-0.17 \\
25 / 5\end{array}$ & $\begin{array}{c}p=0.073 \\
p=0.65\end{array}$ \\
\hline
\end{tabular}


Supplementary Table 2. Primers used in RT-PCR experiments. Note that the Kappa variant 1 corresponds to NCBI Reference Sequence NM_000912.4; the forward primer specifically amplifying this transcript is located at the junction of exons 2 and 3 . The Kappa variant 2 corresponds to NCBI Reference Sequence NM_001282904.1. This isoform has an additional, third exon and therefore contains 5 exons. The forward primer specifically amplifying this transcript is located at the junction of exons 2 and 3 (see Fig.S2).

\begin{tabular}{|c|c|c|c|c|}
\hline Gene & Primer & Primer Sequence & Primer length (bp) & Amplicon size (bp) \\
\hline POMC & $\begin{array}{l}\text { Fwd } \\
\text { Rvs }\end{array}$ & $\begin{array}{c}\text { AAG CGC TAC GGC GGT TTC } \\
\text { TCT TGT AGG CTT CTT GAT GAT G }\end{array}$ & $\begin{array}{l}18 \\
22\end{array}$ & 90 \\
\hline Penk & $\begin{array}{l}\text { Fwd } \\
\text { Rvs }\end{array}$ & $\begin{array}{l}\text { TCC TGG CTT GCG TAA TGG A } \\
\text { CTC CTT GCA GGT TTC CCA AA }\end{array}$ & $\begin{array}{l}19 \\
20\end{array}$ & 68 \\
\hline Pdyn & $\begin{array}{l}\text { Fwd } \\
\text { Rvs }\end{array}$ & $\begin{array}{l}\text { CAA TCC CCT GAT TTG CTC CCT } \\
\text { TCC CCA AGT CCT CCT TGT CA }\end{array}$ & $\begin{array}{l}21 \\
20\end{array}$ & 131 \\
\hline $\mathrm{Mu}$ & $\begin{array}{l}\text { Fwd } \\
\text { Rvs }\end{array}$ & $\begin{array}{c}\text { TTC CGT ACT CCC CGA AAT GC } \\
\text { ACA ATC TAT GGA ACC TTG CCT G }\end{array}$ & $\begin{array}{l}20 \\
22\end{array}$ & 120 \\
\hline Delta & $\begin{array}{l}\text { Fwd } \\
\text { Rvs }\end{array}$ & $\begin{array}{c}\text { GCG GGA AAG CCA GTG ACT C } \\
\text { TGC CCT GTT TAA GGA CTC AGT TG }\end{array}$ & $\begin{array}{l}19 \\
23\end{array}$ & 70 \\
\hline Kappa & $\begin{array}{l}\text { Fwd } \\
\text { Rvs }\end{array}$ & $\begin{array}{l}\text { GAC TTC CGC ACA CCC TTG AA } \\
\text { ATC GAC GTC TTC CCT GAC TT }\end{array}$ & $\begin{array}{l}20 \\
20\end{array}$ & 117 \\
\hline $\begin{array}{c}\text { Kappa } \\
\text { variant } 1\end{array}$ & $\begin{array}{l}\text { Fwd } \\
\text { Rvs }\end{array}$ & $\begin{array}{l}\text { GTT CGT GAT CAT CCG ATA CAC A } \\
\text { CAT CCC CAA AAG GCC AGG AA }\end{array}$ & $\begin{array}{l}22 \\
20\end{array}$ & 143 \\
\hline $\begin{array}{c}\text { Kappa } \\
\text { variant } 2\end{array}$ & $\begin{array}{l}\text { Fwd } \\
\text { Rvs }\end{array}$ & $\begin{array}{l}\text { TCA TGT TCG TGA TCA TCC GGT } \\
\text { GGC CAC TCC AGC CAT TCT TA }\end{array}$ & $\begin{array}{l}21 \\
20\end{array}$ & 130 \\
\hline GAPDH & $\begin{array}{l}\text { Fwd } \\
\text { Rvs }\end{array}$ & $\begin{array}{l}\text { TTG TCA AGC TCA TTT CCT GG } \\
\text { TGT GAG GAG GGG AGA TTC AG }\end{array}$ & $\begin{array}{l}20 \\
20\end{array}$ & 202 \\
\hline b-Actin & $\begin{array}{l}\text { Fwd } \\
\text { Rvs }\end{array}$ & $\begin{array}{l}\text { AAG ACC TGT ACG CCA ACA CA } \\
\text { GCA GTG ATC TCC TTC TGC ATC }\end{array}$ & $\begin{array}{l}20 \\
21\end{array}$ & 85 \\
\hline
\end{tabular}


Supplementary Table 3. Effects of covariates on expression of opioid receptors and peptides in C and CA subjects (as measured by qPCR, see Fig.1). A general linear model was used to analyse group differences as a function of histories of suicide and CA. Pearson correlations between clinical confounders and gene expression levels were assessed for each gene, and only those variables showing a significant correlation were included in each final model.

\begin{tabular}{|c|c|c|c|c|c|}
\hline \multicolumn{6}{|c|}{ Anterior cingulate cortex (ACC) } \\
\hline Gene & Age & Gender & $R I N$ & $P M I$ & $p H$ \\
\hline POMC & $r 2=0.070 ; p=0.058$ & $r 2=0.0035 ; p=0.68$ & $r 2=0.059 ; p=0.083$ & $r 2=0.020 p=0.32$ & $r 2=0.033 ; p=0.19$ \\
\hline Enk & $r 2=0.14 ; p=0.0068^{*}$ & $r 2=0.0020 ; p=0.76$ & $r 2=9.7 E-4 ; p=0.83$ & $r 2=4.5 E-4 ; p=0.88$ & $\mathrm{r} 2=1.7 \mathrm{E}-7 ; p>0.99$ \\
\hline Dyn & $r 2=0.031 ; p=0.21$ & $r 2=0.018 ; p=0.33$ & $r 2=0.16 ; p=0.0032^{*}$ & $r 2=0.021 ; p=0.31$ & $r 2=0.013 ; p=0.41$ \\
\hline $\mathrm{Mu}$ & $r 2=0.0029 ; p=0.71$ & $r 2=0.0080 ; p=0.53$ & $\mathrm{r} 2=0.38 ; \mathrm{p}<0.001^{*}$ & $r 2=3.7 E-7 ; p>0.99$ & $r 2=0.037 ; p=0.17$ \\
\hline Delta & $r 2=0.036 ; p=0.18$ & $r 2=0.013 ; p=0.37$ & $r 2=0.055 ; p=0.093$ & $\mathrm{r} 2=0.019 ; \mathrm{p}=0.32$ & $r 2=0.069 ; p=0.30$ \\
\hline Kappa & $r 2=0.022 ; p=0.29$ & $r 2=0.0096 ; p=0.49$ & $r 2=0.17 ; p=0.0021^{*}$ & $r 2=9.7 E-4 ; p=0.83$ & $r 2=0.075 ; p=0.049^{*}$ \\
\hline \multicolumn{6}{|c|}{ Dorsomedial thalamus (DMT) } \\
\hline Gene & Age & Gender & $R I N$ & PMI & $p H$ \\
\hline POMC & $\mathrm{r} 2=0.0001 ; p=0.94$ & $r 2=0.015 ; p=0.38$ & $r 2=0.0057 ; p=0.59$ & $r 2=0.0028 ; p=0.71$ & $r 2=0.0019 ; p=0.75$ \\
\hline Enk & $r 2=0.026 ; p=0.25$ & $r 2=0.033 ; p=0.19$ & $r 2=0.0023 ; p=0.73$ & $r 2=0.0048 ; p=0.62$ & $r 2=0.037 ; p=0.17$ \\
\hline $\mathrm{Mu}$ & $r 2=0.11 ; p=0.014^{*}$ & $r 2=0.052 ; p=0.10$ & $r 2=0.15 ; p=0.0041^{*}$ & $r 2=0.0063 ; p=0.57$ & $r 2=0.14 ; p=0.0055^{*}$ \\
\hline Delta & $\mathrm{r} 2=0.0011 ; p=0.81$ & $r 2=0.0042 ; p=0.64$ & $r 2=0.14 ; p=0.0050^{*}$ & $r 2=0.0086 ; p=0.51$ & $r 2=0.00061 ; p=0.86$ \\
\hline Kappa & $r 2=0.093 ; p=0.026^{*}$ & $r 2=0.024 ; p=0.27$ & $r 2=0.019 ; p=0.32$ & $r 2=0.020 ; p=0.31$ & $r 2=0.025 ; p=0.26$ \\
\hline \multicolumn{6}{|c|}{ Anterior insula (Al) } \\
\hline Gene & Age & Gender & $R I N$ & $P M I$ & $p H$ \\
\hline POMC & $r 2=0.019 ; p=0.28$ & $r 2=0.039 ; p=0.12$ & $r 2=0.047 ; p=0.087$ & $r 2=0.035 ; p=0.14$ & $r 2=0.030 ; p=0.18$ \\
\hline Enk & $r 2=0.050 ; p=0.078$ & $r 2=0.033 ; p=0.15$ & $r 2=0.021 ; p=0.26$ & $r 2=0.0027 ; p=0.69$ & $r 2=0.019 ; p=0.28$ \\
\hline Dyn & $r 2=0.0084 ; p=0.48$ & $r 2=0.038 ; p=0.13$ & $r 2=0.0041 ; p=0.62$ & $r 2=0.018 ; p=0.29$ & $\mathrm{r} 2=2.4 \mathrm{E}-7 ; \mathrm{p}>0.99$ \\
\hline $\mathrm{Mu}$ & $r 2=0.11 ; p=0.0070^{*}$ & $r 2=0.055 ; p=0.063$ & $r 2=0.10 ; p=0.010^{*}$ & $r 2=0.0099 ; p=0.44$ & $r 2=0.0049 ; p=0.58$ \\
\hline Delta & $r 2=0.0061 ; p=0.54$ & $r 2=0.052 ; p=0.071$ & $r 2=0.0012 ; p=0.79$ & $r 2=0.0023 ; p=0.71$ & $r 2=0.070 ; p=0.036^{*}$ \\
\hline Kappa & $r 2=0.058 ; p=0.058$ & $r 2=3.2 E-5 ; p=0.96$ & $r 2=0.0014 ; p=0.77$ & $r 2=0.0081 ; p=0.48$ & $r 2=0.025 ; p=0.21$ \\
\hline
\end{tabular}


Supplementary Table 4. Effects of covariates on expression of kappa opioid receptor variants in C, CA and SNA subjects (as measured by qPCR, see Fig.2).

\begin{tabular}{|c|c|c|c|c|c|}
\hline \multicolumn{5}{|c|}{ Anterior insula (AI) } \\
\hline Gene & Age & Gender & RIN & $P M I$ & $p H$ \\
\hline Kappa-v1\&2 & $\mathrm{r} 2=0.098 ; \mathrm{p}=0.0023^{*}$ & $\mathrm{r} 2=0.0041 ; \mathrm{p}=0.54$ & $\mathrm{r} 2=0.043 ; \mathrm{p}=0.046^{*}$ & $\mathrm{r} 2=0.0019 ; \mathrm{p}=0.68$ & $\mathrm{r} 2=0.0041 ; \mathrm{p}=0.54$ \\
\hline Kappa-v1 & $\mathrm{r} 2=0.089 ; \mathrm{p}=0.0037^{*}$ & $\mathrm{r} 2=3.2 \mathrm{E}-4 ; \mathrm{p}=0.86$ & $\mathrm{r} 2=0.12 ; \mathrm{p}=0.0011^{*}$ & $\mathrm{r} 2=0.023 ; \mathrm{p}=0.15$ & $\mathrm{r} 2=0.0011 ; \mathrm{p}=0.75$ \\
\hline Kappa-v2 & $\mathrm{r} 2=0.061 ; \mathrm{p}=0.018^{*}$ & $\mathrm{r} 2=0.024 ; \mathrm{p}=0.14$ & $\mathrm{r} 2=0.0050 ; \mathrm{p}=0.50$ & $\mathrm{r} 2=0.0039 ; \mathrm{p}=0.56$ & $\mathrm{r} 2=0.0022 ; \mathrm{p}=0.66$ \\
\hline
\end{tabular}


Supplementary Table 5. Primers for the amplification of bisulfite-converted DNA in NEXTERA experiments.

\begin{tabular}{|c|c|c|c|c|c|}
\hline Primer pair & Primer & Sequence & $\begin{array}{l}\text { Primer } \\
\text { length } \\
\text { (bp) }\end{array}$ & $\begin{array}{l}\text { Amplicon } \\
\text { size (bp) }\end{array}$ & $\begin{array}{c}\text { Annealing } \\
\text { temperature } \\
\left({ }^{\circ} \mathrm{C}\right)\end{array}$ \\
\hline $\begin{array}{l}\text { Kappa_Nextera1 } \\
\text { (exon1) }\end{array}$ & $\begin{array}{l}\text { Fwd } \\
\text { Rvs }\end{array}$ & $\begin{array}{c}\text { TTT GGG GAA GGT TGT ATG } \\
\text { AAC CCA AAA CTT ACC TAT AAT TCC }\end{array}$ & $\begin{array}{l}18 \\
24\end{array}$ & 470 & 60 \\
\hline $\begin{array}{c}\text { Kappa_Nextera2 } \\
\text { (exon2) }\end{array}$ & $\begin{array}{l}\text { Fwd } \\
\text { Rvs }\end{array}$ & $\begin{array}{l}\text { GGG TAA AGT TTG TTT TTT YG } \\
\text { TAA CAT TTC CAA AAT CCT TCA }\end{array}$ & $\begin{array}{l}20 \\
21\end{array}$ & 489 & 59 \\
\hline $\begin{array}{l}\text { Kappa_Nextera3 } \\
\text { (promoter) }\end{array}$ & $\begin{array}{l}\text { Fwd } \\
\text { Rvs }\end{array}$ & $\begin{array}{l}\text { TTG TTT GAG AAG AGA ATG TTT TT } \\
\text { TAA CCC ATC CAA AAA AAA TAA C }\end{array}$ & $\begin{array}{l}23 \\
22\end{array}$ & 441 & 60 \\
\hline $\begin{array}{l}\text { Kappa_Nextera4 } \\
\text { (exon3) }\end{array}$ & $\begin{array}{l}\text { Fwd } \\
\text { Rvs }\end{array}$ & $\begin{array}{c}\text { TTA TTT GAT GAA TTT TTG GTT T } \\
\text { AAA CAC AAA ATT ATT CTA CTT CTC A }\end{array}$ & $\begin{array}{l}22 \\
25\end{array}$ & 424 & 57 \\
\hline $\begin{array}{l}\text { Kappa_Nextera5 } \\
\text { (exon4) }\end{array}$ & $\begin{array}{l}\text { Fwd } \\
\text { Rvs }\end{array}$ & $\begin{array}{l}\text { ATA ATA ATA GGT TTT TGT GTT GTG GT } \\
\text { ATC CCT CAA ATA AAC AAA ATC C }\end{array}$ & $\begin{array}{l}22 \\
23\end{array}$ & 551 & 59 \\
\hline $\begin{array}{c}\text { Kappa_Nextera6 } \\
\text { (variant2 exon) }\end{array}$ & $\begin{array}{l}\text { Fwd } \\
\text { Rvs }\end{array}$ & $\begin{array}{c}\text { ATG AAT TGA GAG ATT TTA AAG GG } \\
\text { AAA AAC TCT AAA AAT CAA TCC TAT CA }\end{array}$ & $\begin{array}{l}23 \\
26\end{array}$ & 437 & 59 \\
\hline $\begin{array}{l}\text { Kappa_Nextera7 } \\
\text { (intron2) }\end{array}$ & $\begin{array}{l}\text { Fwd } \\
\text { Rvs }\end{array}$ & $\begin{array}{c}\text { TGT TGT GTT GTA GGG TTA GTT TT } \\
\text { AAA CAT TTT AAA CAA AAT AAC ACC A }\end{array}$ & $\begin{array}{l}23 \\
25\end{array}$ & 553 & 59 \\
\hline
\end{tabular}


Supplementary Table 6. Primers used during successive rounds of regular PCR in oxBS experiments. Note that: (i) the same "P5UniversalF" primer was use across all samples; (ii) distinct "P7-UniversalR" primers, with different index sequences (underlined below), were used for each sample (single-indexing strategy).

\begin{tabular}{|c|c|c|c|}
\hline \multicolumn{4}{|c|}{ ROUND1 PCR - Primers used for the amplification of genomic DNA. } \\
\hline $\begin{array}{l}\text { Targeted } \\
\text { region in the } \\
\text { Kappa gene }\end{array}$ & Primer & Sequence & $\begin{array}{c}\text { Primer } \\
\text { length } \\
\text { (bp) }\end{array}$ \\
\hline \multirow{2}{*}{ Intron2 } & Fwd & TTT AAG TGT TAT TTT TTT AGT ATG & 24 \\
\hline & Rvs & AAT AAC ACT TTA ACT CAA AAC CAT & 24 \\
\hline \multicolumn{4}{|c|}{$\begin{array}{l}\text { ROUND2 PCR - Primers used for the 2nd round of PCR. } \\
\text { UniversalF and universalR sequences are in shown red and blue, respectively }\end{array}$} \\
\hline $\begin{array}{l}\text { Targeted } \\
\text { region in the } \\
\text { Kappa gene }\end{array}$ & Primer & Sequence & $\begin{array}{c}\text { Primer } \\
\text { length } \\
\text { (bp) }\end{array}$ \\
\hline \multirow{2}{*}{ Intron2 } & Fwd & ACA CTG ACG ACA TGG TTC TAC ANN NTT TAA GTG TTA TTT TTT TAG TAT G & \multirow[t]{2}{*}{49} \\
\hline & Rvs & TAC GGT AGC AGA GAC TTG GTC TNN NAA TAA CAC TTT AAC TCA AAA CCA T & \\
\hline \multicolumn{4}{|c|}{$\begin{array}{l}\text { ROUN3 PCR - Primers used for the 3rd round of PCR, for indexing. } \\
\text { P5 and P7 sequences are shown in red and blue, respectively; 10-base index sequences are underlined. }\end{array}$} \\
\hline Primer & Sample\# & Primer Sequence & $\begin{array}{c}\text { Primer } \\
\text { length } \\
\text { (bp) }\end{array}$ \\
\hline P5-UniversalF & 1 to 47 & AAT GAT ACG GCG ACC ACC GAG ATC T ACA CTG ACG ACA TGG TTC TAC A & 47 \\
\hline Primer & Sample\# & Primer Sequence & $\begin{array}{c}\text { Primer } \\
\text { length } \\
\text { (bp) }\end{array}$ \\
\hline P7-UniversalR & 1 & CAA GCA GAA GAC GGC ATA CGA GAT GTA TCG TCG TTAC GGT AGC AGA GAC TTG GTC T & 56 \\
\hline
\end{tabular}




\begin{tabular}{|c|c|c|c|}
\hline P7-UniversalR & 2 & CAA GCA GAA GAC GGC ATA CGA GAT GTG TAT GCG T TAC GGT AGC AGA GAC TTG GTC T & 56 \\
\hline P7-UniversalR & 3 & CAA GCA GAA GAC GGC ATA CGA GAT IGC TCG TAG T TAC GGT AGC AGA GAC TTG GTC T & 56 \\
\hline P7-UniversalR & 4 & CAA GCA GAA GAC GGC ATA CGA GAT GTC GTC GTC T TAC GGT AGC AGA GAC TTG GTC T & 56 \\
\hline P7-UniversalR & 5 & CAA GCA GAA GAC GGC ATA CGA GAT GTG CGT GTG T TAC GGT AGC AGA GAC TTG GTC T & 56 \\
\hline P7-UniversalR & 6 & CAA GCA GAA GAC GGC ATA CGA GAT GCG TCG TGT A TAC GGT AGC AGA GAC TTG GTC T & 56 \\
\hline P7-UniversalR & 7 & CAA GCA GAA GAC GGC ATA CGA GAT GTC GTG TAC T TAC GGT AGC AGA GAC TTG GTC T & 56 \\
\hline P7-UniversalR & 8 & CAA GCA GAA GAC GGC ATA CGA GAT GAT GTA GCG T TAC GGT AGC AGA GAC TTG GTC T & 56 \\
\hline P7-UniversalR & 9 & CAA GCA GAA GAC GGC ATA CGA GAT GAG TGA TCG T TAC GGT AGC AGA GAC TTG GTC T & 56 \\
\hline P7-UniversalR & 10 & CAA GCA GAA GAC GGC ATA CGA GAT CGC TAT CAG T TAC GGT AGC AGA GAC TTG GTC T & 56 \\
\hline P7-UniversalR & 11 & CAA GCA GAA GAC GGC ATA CGA GAT CGC TGT AGT C TAC GGT AGC AGA GAC TTG GTC T & 56 \\
\hline P7-UniversalR & 12 & CAA GCA GAA GAC GGC ATA CGA GAT GCT AGT GAG T TAC GGT AGC AGA GAC TTG GTC T & 56 \\
\hline P7-UniversalR & 13 & CAA GCA GAA GAC GGC ATA CGA GAT GAG CTA GTG A TAC GGT AGC AGA GAC TTG GTC T & 56 \\
\hline P7-UniversalR & 14 & CAA GCA GAA GAC GGC ATA CGA GAT CGT GCT GTC A TAC GGT AGC AGA GAC TTG GTC T & 56 \\
\hline P7-UniversalR & 15 & CAA GCA GAA GAC GGC ATA CGA GAT GAT CGT CTC T TAC GGT AGC AGA GAC TTG GTC T & 56 \\
\hline P7-UniversalR & 16 & CAA GCA GAA GAC GGC ATA CGA GAT GTG CTG TCG T TAC GGT AGC AGA GAC TTG GTC T & 56 \\
\hline P7-UniversalR & 17 & CAA GCA GAA GAC GGC ATA CGA GAT TGA GCG TGC T TAC GGT AGC AGA GAC TTG GTC T & 56 \\
\hline P7-UniversalR & 18 & CAA GCA GAA GAC GGC ATA CGA GAT CAT GTC GTC A TAC GGT AGC AGA GAC TTG GTC T & 56 \\
\hline P7-UniversalR & 19 & CAA GCA GAA GAC GGC ATA CGA GAT TCA GTG TCT C TAC GGT AGC AGA GAC TTG GTC T & 56 \\
\hline P7-UniversalR & 20 & CAA GCA GAA GAC GGC ATA CGA GAT GTG CTC ATG T TAC GGT AGC AGA GAC TTG GTC T & 56 \\
\hline P7-UniversalR & 21 & CAA GCA GAA GAC GGC ATA CGA GAT CGT ATC TCG A TAC GGT AGC AGA GAC TTG GTC T & 56 \\
\hline P7-UniversalR & 22 & CAA GCA GAA GAC GGC ATA CGA GAT GTC ATG CGT C TAC GGT AGC AGA GAC TTG GTC T & 56 \\
\hline P7-UniversalR & 23 & CAA GCA GAA GAC GGC ATA CGA GAT CTA TGC GAT C TAC GGT AGC AGA GAC TTG GTC T & 56 \\
\hline P7-UniversalR & 24 & CAA GCA GAA GAC GGC ATA CGA GAT TGC TAT GCT G TAC GGT AGC AGA GAC TTG GTC T & 56 \\
\hline P7-UniversalR & 25 & CAA GCA GAA GAC GGC ATA CGA GAT TGT GTG CAT G TAC GGT AGC AGA GAC TTG GTC T & 56 \\
\hline P7-UniversalR & 26 & CAA GCA GAA GAC GGC ATA CGA GAT GAG TGT CAC T TAC GGT AGC AGA GAC TTG GTC T & 56 \\
\hline P7-UniversalR & 27 & CAA GCA GAA GAC GGC ATA CGA GAT CTA GTC TCG T TAC GGT AGC AGA GAC TTG GTC T & 56 \\
\hline
\end{tabular}




\begin{tabular}{|c|c|c|c|}
\hline P7-UniversalR & 28 & CAA GCA GAA GAC GGC ATA CGA GAT GAG TGC ATC T TAC GGT AGC AGA GAC TTG GTC T & 56 \\
\hline P7-UniversalR & 29 & CAA GCA GAA GAC GGC ATA CGA GAT TGC GTA GTC G TAC GGT AGC AGA GAC TTG GTC T & 56 \\
\hline P7-UniversalR & 30 & CAA GCA GAA GAC GGC ATA CGA GAT CTG TGT CGT C TAC GGT AGC AGA GAC TTG GTC T & 56 \\
\hline P7-UniversalR & 31 & 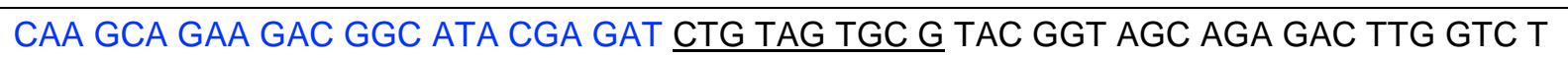 & 56 \\
\hline P7-UniversalR & 32 & CAA GCA GAA GAC GGC ATA CGA GAT GTG CGC TAG T TAC GGT AGC AGA GAC TTG GTC T & 56 \\
\hline P7-UniversalR & 33 & CAA GCA GAA GAC GGC ATA CGA GAT TGT GCT CGC A TAC GGT AGC AGA GAC TTG GTC T & 56 \\
\hline P7-UniversalR & 34 & CAA GCA GAA GAC GGC ATA CGA GAT GAT GCG AGC T TAC GGT AGC AGA GAC TTG GTC T & 56 \\
\hline P7-UniversalR & 35 & CAA GCA GAA GAC GGC ATA CGA GAT CTG TAC GTG A TAC GGT AGC AGA GAC TTG GTC T & 56 \\
\hline P7-UniversalR & 36 & CAA GCA GAA GAC GGC ATA CGA GAT GCG ATG ATG A TAC GGT AGC AGA GAC TTG GTC T & 56 \\
\hline P7-UniversalR & 37 & CAA GCA GAA GAC GGC ATA CGA GAT TGT CGA GTC A TAC GGT AGC AGA GAC TTG GTC T & 56 \\
\hline P7-UniversalR & 38 & CAA GCA GAA GAC GGC ATA CGA GAT GTC TAC TGT C TAC GGT AGC AGA GAC TTG GTC T & 56 \\
\hline P7-UniversalR & 39 & CAA GCA GAA GAC GGC ATA CGA GAT CAG TCA GAG T TAC GGT AGC AGA GAC TTG GTC T & 56 \\
\hline P7-UniversalR & 40 & CAA GCA GAA GAC GGC ATA CGA GAT CGC AGT CTA T TAC GGT AGC AGA GAC TTG GTC T & 56 \\
\hline P7-UniversalR & 41 & CAA GCA GAA GAC GGC ATA CGA GAT GTA TGA GCA C TAC GGT AGC AGA GAC TTG GTC T & 56 \\
\hline P7-UniversalR & 42 & CAA GCA GAA GAC GGC ATA CGA GAT CGA GTG CTG T TAC GGT AGC AGA GAC TTG GTC T & 56 \\
\hline P7-UniversalR & 43 & CAA GCA GAA GAC GGC ATA CGA GAT TAT AGC ACG C TAC GGT AGC AGA GAC TTG GTC T & 56 \\
\hline P7-UniversalR & 44 & CAA GCA GAA GAC GGC ATA CGA GAT TCA TGC GCG A TAC GGT AGC AGA GAC TTG GTC T & 56 \\
\hline P7-UniversalR & 45 & CAA GCA GAA GAC GGC ATA CGA GAT TAT GCG CTG C TAC GGT AGC AGA GAC TTG GTC T & 56 \\
\hline P7-UniversalR & 46 & CAA GCA GAA GAC GGC ATA CGA GAT TCT CTG TGC A TAC GGT AGC AGA GAC TTG GTC T & 56 \\
\hline P7-UniversalR & 47 & CAA GCA GAA GAC GGC ATA CGA GAT CTA TCG CGT G TAC GGT AGC AGA GAC TTG GTC T & 56 \\
\hline
\end{tabular}


Supplementary Table 7. Customized sequencing primers used in oxBS experiments. Note that "+" indicates locked nucleic acids (LNA).

\begin{tabular}{|c|c|c|}
\hline Primer & Primer Sequence & Primer length (bp) \\
\hline universalF-Compl & A+CA+ CTG+ ACG ACA TGG TTC TAC A & 22 \\
\hline universalR-Compl & T+AC+ GGT+ AGC AGA GAC TTG GTC T & 22 \\
\hline universalR-ReverseCompl & A+GA C+CA+ AGT CTC TGC TAC CGT A & 22 \\
\hline
\end{tabular}




\section{Supplementary Table 8.}

\begin{tabular}{|c|c|}
\hline \multicolumn{2}{|c|}{$\begin{array}{l}\text { Primers for cloning the KOR Intron2 into the CpGfree Basic vector. } \\
\text { Restriction sites for enzymatic digestion by Scal (Fwd) and Spel (Rvs) are shown in red. }\end{array}$} \\
\hline Forward & GCAAGAGAAGAGTACTACCCAGAATAACTGA \\
\hline Reverse & CCATTTCACCACTAGTCACACTGCTTTAC \\
\hline \multicolumn{2}{|c|}{$\begin{array}{l}\text { Primers for cloning the KOR Intron2 into the CpGfree Promoter vector. } \\
\text { Restriction sites for enzymatic digestion by BamHI (Fwd) and Spel (Rvs) are shown in red. }\end{array}$} \\
\hline Forward & GCAAGAGAAGGGATCCACCCAGAATAACTGA \\
\hline Reverse & CCATTTCACCACTAGTCACACTGCTTTAC \\
\hline \multicolumn{2}{|c|}{ Primers for Sanger sequencing of the Basic and Promoter vector constructs } \\
\hline Forward & CAATATTGAAAACCACTGATT \\
\hline Reverse & GGCAAACAGCACCTTGATTTC \\
\hline
\end{tabular}

